\title{
New in situ aerosol hyperspectral optical measurements over 300-700 nm - Part 1: Spectral Aerosol Extinction (SpEx) instrument field validation during the KORUS-OC cruise
}

\author{
Carolyn E. Jordan ${ }^{1,2}$, Ryan M. Stauffer ${ }^{3}$, Brian T. Lamb ${ }^{4}$, Charles H. Hudgins ${ }^{2}$, Kenneth L. Thornhill ${ }^{2,5}$, \\ Gregory L. Schuster ${ }^{2}$, Richard H. Moore ${ }^{2}$, Ewan C. Crosbie ${ }^{2,5}$, Edward L. Winstead ${ }^{2,5}$, Bruce E. Anderson ${ }^{2}$, \\ Robert F. Martin ${ }^{2}$, Michael A. Shook ${ }^{2}$, Luke D. Ziemba ${ }^{2}$, Andreas J. Beyersdorf ${ }^{2,6}$, Claire E. Robinson ${ }^{2,5}$, \\ Chelsea A. Corr ${ }^{2,7}$, and Maria A. Tzortziou ${ }^{3,4}$ \\ ${ }^{1}$ National Institute of Aerospace, Hampton, Virginia, USA \\ ${ }^{2}$ NASA Langley Research Center, Hampton, Virginia, USA \\ ${ }^{3}$ NASA Goddard Space Flight Center, Greenbelt, Maryland, USA \\ ${ }^{4}$ Earth and Atmospheric Sciences, City University, City University of New York, New York, New York, USA \\ ${ }^{5}$ Science Systems and Applications Inc., Hampton, Virginia, USA \\ ${ }^{6}$ Chemistry and Biochemistry, California State University, San Bernardino, San Bernardino, California, USA \\ ${ }^{7}$ Springfield College, Springfield, Massachusetts, USA
}

Correspondence: Carolyn E. Jordan (carolyn.jordan@nasa.gov)

Received: 7 August 2020 - Discussion started: 19 August 2020

Revised: 20 November 2020 - Accepted: 30 November 2020 - Published: 29 January 2021

\begin{abstract}
In situ observations of spectrally resolved aerosol extinction coefficients $(300-700 \mathrm{~nm}$ at $\sim 0.8 \mathrm{~nm}$ resolution) from the May-June 2016 Korea-United States Ocean Color (KORUS-OC) oceanographic field campaign are reported. Measurements were made with the custom-built Spectral Aerosol Extinction (SpEx) instrument that previously has been characterized only using laboratory-generated aerosols of known size and composition. Here, the performance of SpEx under realistic operating conditions in the field was assessed by comparison to extinction coefficients derived from commercial instruments that measured scattering and filter-based absorption coefficients at three discrete visible wavelengths. Good agreement was found between these two sets of extinction coefficients with slopes near unity for all three wavelengths within the SpEx measurement error $\left( \pm 5 \mathrm{Mm}^{-1}\right)$. The meteorological conditions encountered during the cruise fostered diverse ambient aerosol populations with varying sizes and composition at concentrations spanning 2 orders of magnitude. The sampling inlet had a $50 \%$ size cut of $1.3 \mu \mathrm{m}$ diameter particles such that the in situ aerosol sampling suite deployed aboard ship measured finemode aerosols only. The extensive hyperspectral extinction
\end{abstract}

data set acquired revealed that nearly all measured spectra exhibited curvature in logarithmic space, such that Ångström exponent $(\alpha)$ power law fits could lead to large errors compared to measured values. This problem was particularly acute for $\alpha$ values calculated over only visible wavelengths and then extrapolated to the UV, highlighting the need for measurements in this wavelength range. Second-order polynomial fits to the logarithmically transformed data provided a much better fit to the measured spectra than the linear fits of power laws. Building on previous studies that used total column aerosol optical depth observations to examine the information content of spectral curvature, the relationship between $\alpha$ and the second-order polynomial fit coefficients $\left(a_{1}\right.$ and $a_{2}$ ) was found to depend on the wavelength range of the spectral measurement such that any given $\alpha$ maps into a line in $\left(a_{1}, a_{2}\right)$ coefficient space with a slope of $-2 \operatorname{LN}\left(\lambda_{c h}\right)$, where $\lambda_{\mathrm{ch}}$ is defined as the single wavelength that characterizes the wavelength range of the measured spectrum (i.e., the "characteristic wavelength"). Since the curvature coefficient values depend on $\lambda_{\mathrm{ch}}$, it must be taken into account when comparing values from spectra obtained from measurement techniques with different $\lambda_{\text {ch }}$. Previously published work has 
shown that different bimodal size distributions of aerosols can exhibit the same $\alpha$ yet have differing spectral curvature with different $\left(a_{1}, a_{2}\right)$. This implies that $\left(a_{1}, a_{2}\right)$ contain more information about size distributions than $\alpha$ alone. Aerosol size distributions were not measured during KORUS-OC, and the data reported here were limited to the fine fraction, but the $\left(a_{1}, a_{2}\right)$ maps obtained from the SpEx data set are consistent with the expectation that $\left(a_{1}, a_{2}\right)$ may contain more information than $\alpha$ - a result that will be explored further with future SpEx and size distribution data sets.

\section{Introduction}

Significant natural variability in the size and composition of atmospheric aerosols introduces uncertainty into the representation of their optical properties and radiative impacts in models and satellite retrievals. While numerous airborne and surface-based observations over past decades have placed important constraints on these relationships, measurements have been typically limited to only one or a few wavelengths of light, which are extrapolated across the ultraviolet (UV)-visible-infrared (IR) spectrum by assuming a power law relationship (e.g., the well-known Ångström exponent). However, there is long-standing evidence that extinction and aerosol optical depth spectra in the ambient atmosphere exhibit curvature that is not fully captured by a power law (e.g., King and Byrne, 1976; King et al., 1978; Kaufman, 1993; Reid et al., 1999; Eck et al., 1999, 2001a, b, 2003a, b; O'Neill et al., 2001; Schuster et al., 2006; Kaskaoutis et al., 2010, 2011; Rao and Niranjan, 2012). This wavelength dependence of the aerosol extinction is thought to be driven primarily by the particle size distribution with only a minor contribution from the compositionally dependent aerosol absorption (Eck et al., 2001b; Schuster et al., 2006). However, these relationships remain largely qualitative and stem from columnar remote sensing measurements and Mie theory calculations. This motivates the incorporation of recently developed, advanced instruments for measuring in situ, hyperspectral aerosol extinction into field campaigns that study the ambient atmosphere.

It is important to note that the power law assumption is empirical. Used to describe the interaction between light and aerosols (e.g., Ångström, 1989; Moosmüller and Chakrabarty, 2011),

$p(\lambda)=\beta \lambda^{-\alpha}$,

$p$ may represent various optical parameters of interest (e.g., scattering, absorption, extinction), $\lambda$ is the wavelength of light $(\mu \mathrm{m}), \beta$ is $p$ at $1 \mu \mathrm{m}$, and $\alpha$ is the Ångström exponent. One advantage of this representation is that the derivative of this relationship produces a line in logarithmic space with a wavelength-independent slope,

$\alpha=-\frac{\mathrm{dLN}(p(\lambda))}{\mathrm{dLN}(\lambda)}$.

Hence, from any two wavelengths, the Ångström exponent for the entire spectrum can be determined via

$\alpha=-\frac{\operatorname{LN}\left(p\left(\lambda_{2}\right) / p\left(\lambda_{1}\right)\right)}{\operatorname{LN}\left(\lambda_{2} / \lambda_{1}\right)}$.

The simplicity of this representation has led to its widespread use in the aerosol and remote sensing communities due to its utility in calculating $p(\lambda)$ at wavelengths for which there is not a direct measurement. $\alpha$ is sensitive to the measurement error in $p(\lambda)$, such that if multiple wavelengths are available, it is preferable to perform a linear fit using Eq. (2) than a paired wavelength calculation as in Eq. (3). If the optical property of interest is fully described by a power law, then further spectral detail beyond several wavelengths is superfluous. However, if $\alpha$ is not, in fact, wavelength-independent for ambient aerosols, then a hyperspectral measurement (or sufficient wavelength sampling spanning the full wavelength range of interest) is required to capture the actual wavelength dependence.

Previous studies have considered various aerosol properties that may influence the spectral shape (and/or variation of the Ångström exponents calculated from different pairs of wavelengths) of ambient aerosol optical depth (AOD) such as the volume mean (or effective) radius of accumulation-mode aerosols, the geometric SD (i.e., width) of the accumulation mode, the volume fraction of the fine mode relative to the total aerosol population, and the absorption characteristics (i.e., composition) of the aerosol population (e.g., Reid et al., 1999; Eck et al., 1999, 2001b; Schuster et al., 2006). The relationships identified to date remain qualitative rather than quantitative and have been based on total atmospheric column measurements from remote sensors and on Mie calculations. Recently, the retrieval algorithm developed by O'Neill et al. $(2001,2003,2008)$ to distinguish fine mode from coarse-mode AOD components using second-order spectral fits has been applied to in situ extinction components based on scattering and absorption measurements made at a few visible wavelengths and evaluated using several sets of field data (Kaku et al., 2014, and references therein). The Spectral Aerosol Extinction (SpEx) instrument (Jordan et al., 2015) provides a new measurement approach that combines the advantages of a broad spectral range (typically limited to remote sensing techniques) with an in situ measurement capability (that allows for direct comparison to other in situ measurements of ambient aerosol microphysical and chemical properties). Combining this hyperspectral in situ measurement capability with retrieval techniques as in Kaku et al. (2014) also provides a new tool to fine-tune remote sensing retrievals.

Although SpEx measures a narrower wavelength range (300-700 nm) than some remote sensors - e.g., ground-based 
nine-band sun-sky radiometers AERONET (340-1640 nm, Giles et al., 2019) and airborne hyperspectral sun-sky radiometer 4STAR (350-1750 $\mathrm{nm}, 2-3 \mathrm{~nm}$ resolution, LeBlanc et al., 2020) - and similar ranges to others - e.g., hyperspectral polarimeters SPEX airborne $(400-800 \mathrm{~nm}, 2-3 \mathrm{~nm}$ resolution in intensity, Smit et al., 2019; Fu et al., 2020) and SPEXone $(385-770 \mathrm{~nm}, 2 \mathrm{~nm}$ resolution in intensity, Hasekamp et al., 2019) planned for the upcoming PACE mission (Werdell, et al., 2019; Remer et al., 2019a, b) it measures deeper into the UV range and has finer spectral resolution, $\sim 0.8 \mathrm{~nm}$. Similar in situ instruments, such as broadband cavity-enhanced spectroscopy (BBCES) instruments (e.g., Washenfelder et al., 2013, 2015; Bluvshtein et al., 2016, 2017; He et al., 2018), do not provide as broad a UV-visible range as SpEx. Hence, SpEx is particularly suited to examine spectral details for ambient aerosols over its measurement range and to relate those spectral details to simultaneous in situ measurements of ambient aerosol microphysics and composition.

Previous work described SpEx using a series of laboratory tests that included a variety of non-absorbing and absorbing aerosols to characterize the instrument (Jordan et al., 2015). However, the purpose of SpEx is to measure atmospheric aerosols in the ambient environment. Hence, this paper is the first to offer details on the instrument performance in the field. The data presented here were obtained during the Korea-United States Ocean Color (KORUS-OC) oceanographic field campaign conducted around the Korean peninsula under the leadership of the Korean Institute of Ocean Science and Technology (KIOST) and the US National Aeronautics and Space Administration (NASA). The KORUSOC cruise was affiliated with the airborne Korea-United States Air Quality (KORUS-AQ) campaign and the KOrean Coastal water Ocean and Atmosphere (KOCOA) field campaign. These joint missions were conducted to study South Korean air quality and ocean color within the field of regard of South Korea's Geostationary Ocean Color Imager (GOCI) that provided hourly ocean color and aerosol optical depth (AOD) measurements. Although the primary scientific objectives of the KORUS-OC cruise focused on ocean color measurements (both in situ and remotely sensed), there were also objectives to address atmospheric correction requirements and to explore interdisciplinary science questions (e.g., Tzortziou et al., 2018; Thompson et al., 2019). The joint S. Korean and US-based science teams sailed aboard the KIOST research vessel R/V Onnuri (Fig. S1 in the Supplement). Details on the scientific objectives of these field campaigns are provided in two white papers: Al Saadi et al. (2015) and US-Korean Steering Group (2015). An overview of the findings from KORUS-AQ is provided by Crawford et al. (2020) and references therein.

Two commercial instruments (AirPhoton's integrating nephelometer, IN101, and Brechtel's Tricolor Absorption Photometer, TAP) were also deployed to measure in situ aerosols at three visible wavelengths providing scattering coefficients and absorption coefficients, respectively. These measurements are presented in detail here and used to evaluate the performance of SpEx. Filter samples were also collected and analyzed in the laboratory for spectral absorption and chemical composition as discussed in Part 2 of this work. Those data provide additional context for the measurements described here in Part 1. Further, Part 2 presents an assessment of the applicability of a methodology routinely used by the ocean color community to measure hyperspectral particle absorption for use with ambient atmospheric aerosol samples. Hence, Part 2 includes further discussion of the ability of power laws to fully represent the observed hyperspectral variability of in situ aerosol optical properties as measured during KORUS-OC.

\section{Methods}

\subsection{Ship deployment}

The measurements reported here from 20:25 KST 21 May through 09:00 KST 4 June 2016 (Korean standard time, $\mathrm{KST}=\mathrm{UTC}+9)$ were made outside of South Korea's territorial seas ( $>12$ nautical miles, $22.2 \mathrm{~km}$, from the coast, Fig. 1a). The instrument suite (Fig. S2) was deployed above the bridge strapped to the starboard rail in a custom-built box designed to keep the instruments dry yet ventilated to prevent overheating (Fig. S1). The pumps were located in a separate box a few meters away tied to the stern rail (Fig. S1) to limit thermal and mechanical interference with the measurements. Measurements were made at ambient temperature $(T)$, pressure $(P)$, and relative humidity $(\mathrm{RH})$, (i.e., the aerosols were not dried prior to measurement) with the exception of the TAP instrument which is internally heated and kept at a constant $35^{\circ} \mathrm{C} . T, P$, and RH were measured both aboard ship and within the sampling system. Although the sampling box was ventilated, it was not climate controlled. On the top deck it was in direct sunlight during the day, and even at night various components in the system kept the interior warmer and drier than ambient air. These conditions led to diurnal variability in the difference between sampling and ambient conditions, such that the sampling $T$ was $\sim 6^{\circ} \mathrm{C}$ warmer at night, increasing to as much as $\sim 15^{\circ} \mathrm{C}$ warmer in mid-afternoon. Similarly, ambient RH ranged from 55\%-98\% RH throughout the cruise, while the sampling RH ranged from $\sim 30 \%-$ $70 \%$. For the purposes of this work (both Parts 1 and 2), the comparisons made are all within this sampling system with $T$ and RH consistent across all measurements, except for TAP. Since non-volatile black carbon (BC) is expected to dominate the absorption measurement, this difference is expected to have a limited impact on the results. The primary objective in this work is to evaluate the performance of SpEx by direct comparisons to the data from the two commercial instruments in the measurement suite. Hence, we did not perform any corrections to either ambient $T$ and $\mathrm{RH}$ or to 
standard temperature and pressure (STP) prior to comparing these data. There are no comparisons in this pair of papers to other data sets, so such corrections are not necessary for this study.

The available berths aboard ship constrained the number of personnel available to operate the sampling system, so it was necessary to configure the system to operate nearly autonomously. To ensure that water did not enter the sampling line, a tall stainless-steel sampling mast (19.05 mm (3/4 in.) inner diameter tubing) was used to minimize the chance of sea spray entering the line from below. Further, the inlet was attached to the vertical sampling mast with a curved section of stainless-steel tubing such that the inlet was downward facing to prevent any potential precipitation from entering the line from above as well (Fig. S1). This configuration worked as intended with the inlet approximately $10 \mathrm{~m}$ above the sea surface. However, the fast flow rate required for the SpEx measurement (approximately $70 \mathrm{~L} \mathrm{~min}^{-1}$ ) through the curved inlet resulted in the removal of coarse aerosol with a $50 \%$ size cut of $\sim 1.3 \mu \mathrm{m}$ diameter (Fig. S3). Hence, all of the measurements here (sampling from the same inlet, Fig. S2) reflect only the fine-fraction aerosol in the marine boundary layer (MBL).

While the SpEx and commercial instruments were run mostly uninterrupted, colleagues from other groups aboard ship carried out the routine filter changes needed throughout the cruise. They also ensured that the system ran properly and were there to handle problems. The methodology and results of the filter sampling will be presented in the companion paper (Part 2, Jordan et al., 2021).

\subsection{Aerosol scattering and absorption coefficient measurements and derived parameters}

The IN101 and TAP instruments provide data at a higher temporal resolution than SpEx and were deployed with two objectives: (1) to identify and flag incidents of ship exhaust ("plume") contamination of the data set and (2) to evaluate the new spectral measurements (both from SpEx and the filters). The TAP (model 2901, Brechtel, Hayward, CA) measures absorption coefficients $\left(\sigma_{\text {abs }}\right)$ at 467,528 , and $652 \mathrm{~nm}$ with $1 \mathrm{~s}$ resolution, and the IN101 (AirPhoton, Baltimore, MD) measures scattering coefficients $\left(\sigma_{\text {scat }}\right)$ at 450,532 , and $632 \mathrm{~nm}$ with $\sim 10$ s resolution.

To identify ship plume interceptions, an initial examination of the IN101 $\sigma_{\text {scat }}$ and TAP $\sigma_{\text {abs }}$ data was performed. One-minute averages were calculated in order to calculate the single-scattering albedo $\left(\omega=\sigma_{\text {scat }} /\left(\sigma_{\text {scat }}+\sigma_{\text {abs }}\right)\right)$. The $\sigma_{\text {scat }}$ data were corrected using the submicron factors in Anderson and Ogren (1998). These corrections are needed to resolve truncation errors in the forward scattering (the 7 to $0^{\circ}$ range missing from the measurement) and non-Lambertian errors that arise from the distribution of light by the opal glass diffusor. Due to limited personnel, calibrations were not performed during the cruise. Pre- and post-cruise cali- brations using pure $\mathrm{CO}_{2}$ were performed in the laboratory to correct the final archived data and indicate the instrument performance was stable throughout the measurement period. The $\sigma_{\text {abs }}$ data were corrected for scattering as recommended in Ogren et al. (2017).

Interception of the ship plume was first identified using 1 min averages of the gas-phase $\mathrm{NO}_{2}$ and $\mathrm{O}_{3}$ measurements (Thompson et al., 2019). The inlets for the gas-phase instruments were near but not co-located with the aerosol inlet, so the $1 \mathrm{~min}$ averages of $\omega, \sigma_{\mathrm{abs}}$, and $\sigma_{\text {scat }}$ were used to further assess evident ship plume interceptions in the aerosol data set. The $\sigma_{\text {abs }}$ data were particularly sensitive to such interceptions exhibiting dramatic brief spikes in the otherwise smoothly varying time series (the interested reader can compare $\sigma_{\mathrm{abs}}$ in Fig. S4, which shows all of the data in the time series, including ship plume interceptions to $\sigma_{\mathrm{abs}}$ in Fig. 2a, where the plume interceptions have been removed). These were easily identifiable and removed manually. The inlets for the in situ instruments were towards the starboard bow (gas phase on a lower deck, a few meters aft of the aerosol inlet) opposite of the ship stack pointed toward the port side stern. While underway, ship plumes did not affect the measurements, but they were encountered occasionally when on station or, as was more frequently the case, when getting underway from a stationary sampling site. The archived plume flags ( $=0$ for ambient air, 1 for ship plume interceptions) may be used to either remove data points affected by ship contamination or to assess ship plume contamination of filter samples (see Part 2).

In addition to the $1 \mathrm{~min}$ averaged $\sigma_{\text {scat }}$ and $\sigma_{\text {abs }}$ data reported in the KORUS-AQ data archive, averages were also calculated for each $30 \mathrm{~s}$ SpEx sampling interval and corrected in the same manner as the $1 \mathrm{~min}$ data set. The IN101 and TAP instruments measure at different wavelengths, so in order to calculate $\sigma_{\text {ext }}\left(=\sigma_{\text {scat }}+\sigma_{\text {abs }}\right)$, the TAP data were adjusted to the IN101 wavelengths using Eq. (3). For clarity, these extinction coefficients are denoted NT (for nephelometer $+\mathrm{TAP}) \sigma_{\mathrm{ext}}$ in comparison to the measured SpEx $\sigma_{\mathrm{ext}}$ at those wavelengths $(450,532$, and $632 \mathrm{~nm})$. Similarly, a second set of plume flags was created for the SpEx sampling interval (i.e., based on plume interceptions for $30 \mathrm{~s}$ intervals approximately every $4 \mathrm{~min}$; see Sect. 2.3).

\subsection{Spectrally resolved aerosol extinction coefficient measurements}

Developed from a prototype described in Chartier and Greenslade (2012) SpEx is described in detail in Jordan et al. (2015). SpEx is a White-type optical cell (White, 1942) with a $39.4 \mathrm{~m}$ path length and a $17 \mathrm{~L}$ internal volume. A flush time of $90 \mathrm{~s}$ completely exchanges the air in the cell ( 3 times the volume) for flow rates $>34 \mathrm{~L} \mathrm{~min}^{-1}$; here, the flow rate was $\sim 70 \mathrm{~L} \mathrm{~min}^{-1}$. The optical cell is coupled via fiber optics to a UV5000 system (Cerex Monitoring Solutions, LLC, Atlanta, GA) with a $150 \mathrm{~W}$ xenon lamp source (Cerex P/N CRX- 

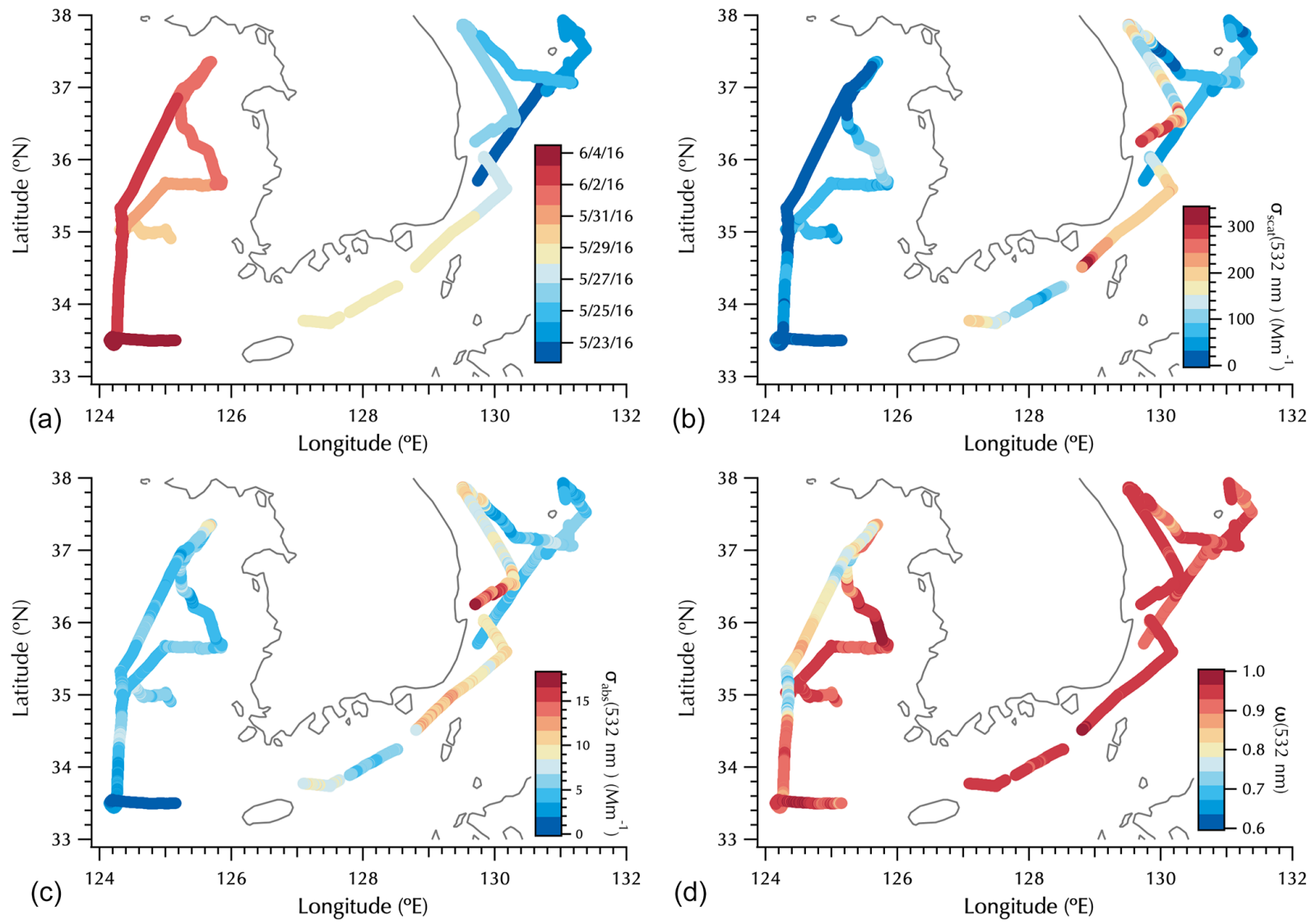

Figure 1. Cruise maps of date and time $(\mathrm{KST}, \mathbf{a})$ with $532 \mathrm{~nm} \sigma_{\text {scat }}\left(\mathrm{Mm}^{-1}, \mathbf{b}\right), \sigma_{\mathrm{abs}}\left(\mathrm{Mm}^{-1}, \mathbf{c}\right)$, and $\omega(\mathbf{d})$.

X150W), integrated with an Ocean Optics, Inc. (Dunedin, FL) QE65Pro 16 bit spectrometer. Sampling for $30 \mathrm{~s}$ using an integration time of $\sim 20-50 \mathrm{~ms}$ optimizes the signal-to-noise ratio for each measured intensity spectrum (Jordan et al., 2015). An automated valve system controls the 4 min sampling cycle by switching the flow between the filtered line (ambient air without aerosols) and an unfiltered line (ambient air with aerosols): $90 \mathrm{~s}$ flush, $30 \mathrm{~s}$ sample without aerosols, $90 \mathrm{~s}$ flush, $30 \mathrm{~s}$ sample with aerosols, and repeat.

The intensity spectrum is measured for the sample without aerosols for a reference $\left(I_{0}(\lambda)\right)$ and for the sample with aerosols $(I(\lambda))$ from which the extinction spectra $\left(\sigma_{\text {ext }}(\lambda)\right)$ are calculated using the extinction law (Eq. 4),

$\sigma_{\mathrm{ext}}(\lambda)=\frac{-\mathrm{LN}\left(I(\lambda) / I_{0}(\lambda)\right)}{L}$,

where $\lambda$ is the wavelength of light and $L$ is the optical path length (here, in units of $\mathrm{Mm}$ ). Hence, extinction spectra are acquired every $4 \mathrm{~min}$. Reference spectra before and after each sample spectrum are averaged together to account for drift in the intensity between measurements in the calculation of $\sigma_{\text {ext }}$. A particular strength of this measurement is it explicitly accounts for extinction arising from gas-phase constituents via the reference spectra. No calibrations are needed to obtain aerosol $\sigma_{\text {ext }}$. Laboratory tests have shown the measurement error over the full spectral range of the measurements (300$700 \mathrm{~nm}$ ) to be about $\pm 5 \mathrm{Mm}^{-1}$ (Jordan et al., 2015).

Several modifications have been made to the instrument since the laboratory studies reported in Jordan et al. (2015). These include an automated switching system between valves that control flow between filtered and unfiltered air and new custom control software that allows for continuous unattended operation. Further, the metal-jacketed optical fibers used previously were replaced with bare optical fibers securely packed in foam to reduce noise when deployed on mobile platforms. This last change resulted in greatly improved data quality with far fewer spectra disrupted due to mechanical disturbance under field conditions. Nonetheless, some spectra had to be rejected from the final data set due to features that provided clear evidence of disturbance. Typically, this occurred around the times of the filter changes when the lid of the box housing the sampling system needed to be raised to change filters (flagged using the plume flag field, value set to 2; see Fig. S4). Sometimes the filters were changed during flush times, leaving measured spectra unaffected, while at other times, disturbed spectra persisted for some period of time around the filter change. This suggests other vibrations arising from work involving nearby instru- 

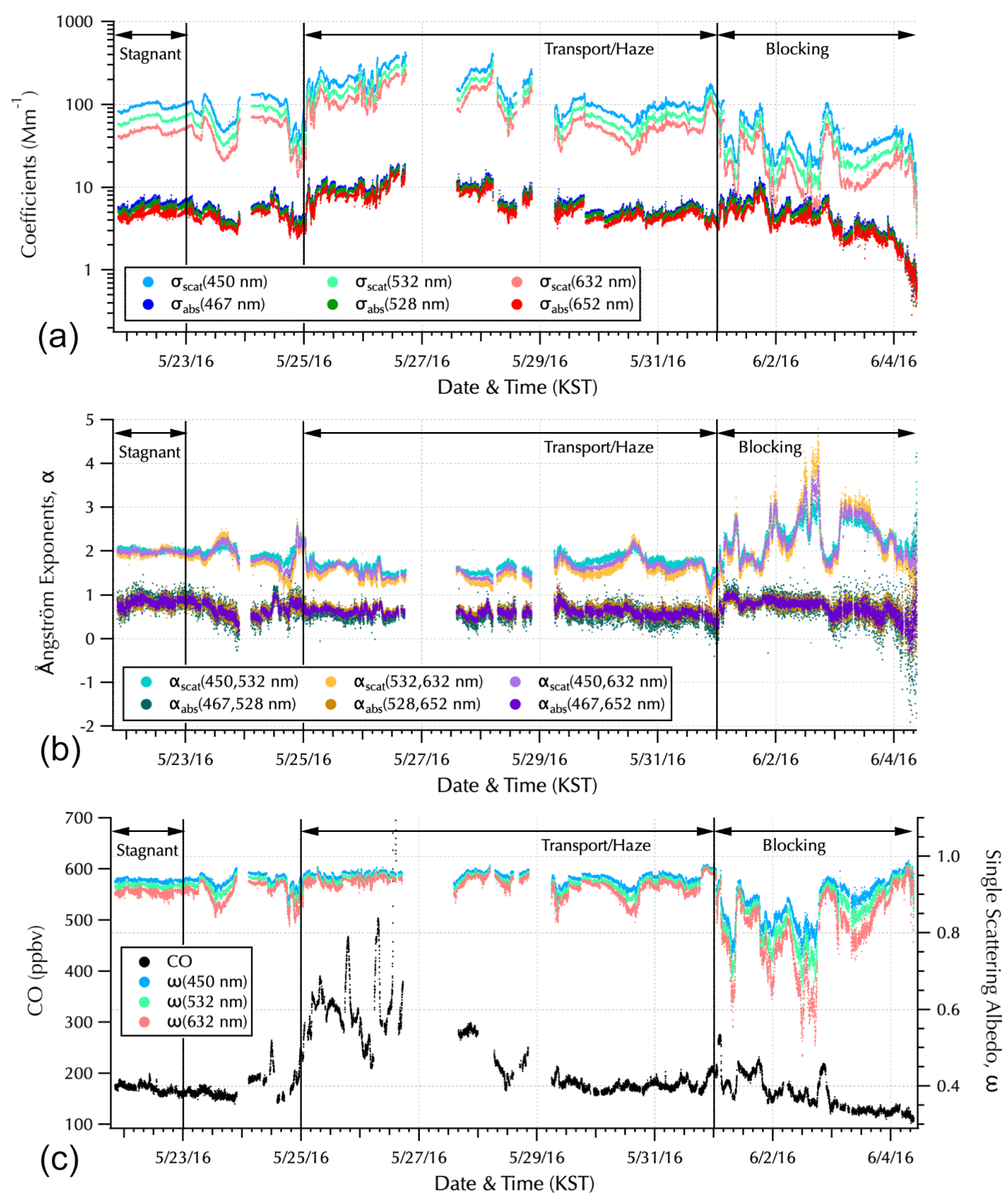

Figure 2. (a) $\sigma_{\text {scat }}$ (light shades) and $\sigma_{\text {abs }}$ (dark shades) averaged to 1 min intervals during the cruise (both in units of $\mathrm{Mm}^{-1}$ ). (b) $\alpha_{\mathrm{scat}}($ light shades) and $\alpha_{\text {abs }}$ (dark shades), unitless, calculated from the wavelength pairs of the coefficients in the top panel. (c) $\omega$ (right axis), unitless, along with $1 \mathrm{~min}$ averaged $\mathrm{CO}$ concentrations (ppbv). Note that the peak CO value cutoff in the figure reached $1000 \mathrm{ppbv}$.

ments or elsewhere on the ship may have contributed to the noisy rejected spectra. More work is required to further reduce the susceptibility of $\mathrm{SpEx}$ to sources of vibrational noise; nonetheless $<8 \%$ of the 4255 measured spectra were rejected from the data set overall. Note that ship plume interception (affecting $<6 \%$ of the measured spectra) often resulted in distorted spectra likely due to rapid changes in both the aerosol population and the gas-phase concentrations used to establish the reference spectrum for the calculation of aerosol extinction as in Eq. (4). Hence, only spectra obtained when the plume flag $=0$ should be used for analysis of ambient conditions.

One consequence of unattended operation is the intensity drift sometimes resulted in saturated pixels around 332 and $467 \mathrm{~nm}$ due to peaks at those wavelengths in the lamp spectrum (Fig. S5). Saturation can be prevented either by adjusting the integration time of the spectrometer or by realigning the optics. However, unattended operation necessitated fil- 
tering the spectra at those two wavelengths when saturation occurred. The 16 bit spectrometer has a maximum intensity count of $65536\left(2^{16}\right)$; however, saturation effects became apparent before reaching this maximum. Tests showed that a threshold of 63000 counts was a suitable limit for removing saturation effects from the spectrum. Filtering the $467 \mathrm{~nm}$ channel and the two adjacent pixels on either side of that channel removed the saturation distortions completely. The saturation effects at $332 \mathrm{~nm}$ were filtered in the same way; however, there appeared to be a minor shoulder effect that extended over a broader wavelength range in the UV. The effect was minimal (a few percent of the measured value) and well within the measurement error. However, caution is recommended against overinterpreting the shape of a spectrum in the vicinity of $332 \mathrm{~nm}$ when the saturation flag (Sat332Flag) for this channel is set to 1 . Saturation at $332 \mathrm{~nm}$ affected $16 \%$ of the total 4255 measured spectra.

\section{Results}

\subsection{Overview of $\sigma_{\text {scat }}$ and $\sigma_{\text {abs }}$ during KORUS-OC}

Four distinct synoptic meteorological regimes have been described in detail for the KORUS-AQ period (Peterson et al., 2019). The KORUS-OC cruise departed the peninsula (Fig. 1a) sailing to the East Sea (Sea of Japan) near the end of the second of these periods, the Stagnant period, characterized by limited transport and enhanced photochemical production of secondary organic aerosols (SOAs; Kim et al., 2018; Nault et al., 2018; Choi et al., 2019; Jordan et al., 2020). This regime started breaking down on 23 May, followed by a precipitation event on 24 May that reduced ambient aerosols to low concentrations as reflected by low (tens of $\mathrm{Mm}^{-1}$ ) $\sigma_{\text {scat }}$ (Fig. 2a).

From 25 through 31 May the Transport/Haze period was characterized by air mass transport (from the west/northwest carrying pollutants from China), overcast hazy conditions, and rapid local South Korean secondary production of inorganic aerosols resulting in the largest concentrations of the $\mathrm{PM}_{2.5}$ fraction of aerosols (i.e., particulate matter with diameters $\leq 2.5 \mu \mathrm{m}$ ) observed during the KORUS-AQ campaign (Peterson et al., 2019; Eck et al., 2020; Jordan et al., 2020). The greatest $\sigma_{\text {scat }}$ values (hundreds of $\mathrm{Mm}^{-1}$ ) observed aboard the R/V Onnuri were found during the first half of the Transport/Haze period while the ship was downwind of the Korean peninsula in the East Sea (Figs. 1a and b, and 2a). Lower $\sigma_{\text {scat }}$ values were observed during this period when the ship was upwind of the peninsula following its transit to the West Sea (Yellow Sea).

The final of the four synoptic periods, the Blocking period, followed a frontal passage that ended the previous Transport/Haze period (Peterson et al., 2019). This final frontal passage swept in cleaner air from the north, leading to a rapid decrease in aerosol concentrations reflected in the reduced $\sigma_{\text {scat }}$ observed aboard ship (Fig. 2). The Blocking period was then characterized by limited transport and occasional brief stagnant periods due to adjacent high- and low-pressure systems with the high poleward of the low (called a Rex block). Under these conditions local sources dominated pollutants, but aerosols did not accumulate to large concentrations (Peterson et al., 2019; Jordan et al., 2020). This led to strikingly low $\sigma_{\text {scat }}$ values (tens to $<10 \mathrm{Mm}^{-1}$, Fig. 2), even lower than those observed during the precipitation event on 24 May.

Throughout the cruise $\sigma_{\text {abs }}$ values were typically an order of magnitude smaller than $\sigma_{\text {scat }}$ (Fig. 2a) with peak values generally found at the same locations and times as peak $\sigma_{\text {scat }}$ (Fig. 1). Hence, while the temporal variability of $\sigma_{\text {abs }}$ largely followed $\sigma_{\text {scat }}$, the range in the magnitude of $\sigma_{\text {abs }}(0.36$ $\left.18.07 \mathrm{Mm}^{-1}\right)$ at $532 \mathrm{~nm}$ was far less than that of $\sigma_{\text {scat }}(2.8$ $\left.332.2 \mathrm{Mm}^{-1}\right)$. This led to the finding that single-scattering albedo values $\left(\omega(\lambda)=\sigma_{\text {scat }}(\lambda) / \sigma_{\text {ext }}(\lambda)\right)$ were driven by the change in scattering not absorption. Typically, $\omega$ was $>0.9$ (Figs. 1d and 2c). The excursions below this value observed on 23 and 24 May occurred when the reduction in $\sigma_{\text {scat }}$ exceeded that observed in $\sigma_{\text {abs }}$.

The most extreme low values of $\omega(\sim 0.7$ for $532 \mathrm{~nm}$, Figs. 1 and 2), however, occurred during the Blocking period, when the temporal evolution of $\sigma_{\text {abs }}$ did not closely follow $\sigma_{\text {scat. }}$. At that time, the scattering Ångström exponents $\left(\alpha_{\text {scat }}\right)$ increased to values $>3$, while absorption Ångström exponents $\left(\alpha_{\text {abs }}\right)$ were $\sim 1$ (Fig. 2b). These data indicate that the aerosol population was dominated by small particles, likely black carbon (BC). The temporal evolution of carbon monoxide (CO, Fig. 2c) and $\sigma_{\text {scat }}$ (Fig. 2a) was strikingly similar from 04:00 1 June through 20:00 2 June, exhibiting an $r^{2}=0.841$ for a linear regression over that time. This is in contrast to the Blocking period as a whole $\left(r^{2}=0.514\right)$ or the rest of the campaign, excluding the Blocking period $\left(r^{2}=0.623\right)$. The good correlation with $\mathrm{CO}$, the BC signature in $\alpha_{\mathrm{abs}}$, the small particle population indicated by $\alpha_{\text {scat }}$, and the limited transport of the Blocking period together suggest that the low $\omega$ values arose from local ship emissions from either commercial or fishing vessels or both. Note that the inference that aerosols during the Blocking period were from local ship emissions refers to the regional ambient environment and should not be confused with ship plume contamination from the R/V Onnuri (see Sect. 2.2 for the criteria used to remove ship stack contamination from the data set).

Aside from the Blocking period, $\alpha_{\text {scat }}$ typically ranged from $\sim 1.5-2$, with evident wavelength dependence in the $\alpha_{\text {scat }}$ wavelength pairs (Fig. 2b). Little difference was found among the wavelength pairs in the $\alpha_{\text {abs }}$ values that typically ranged from $\sim 0.5-1$ throughout the cruise.

\subsection{Comparison of SpEx data to $\sigma_{\text {ext }}$ calculated from $\sigma_{\text {scat }}+\sigma_{\text {abs }}$}

$\sigma_{\text {ext }}$ values calculated from the $\sigma_{\text {scat }}+\sigma_{\text {abs }}$ data (denoted NT $\sigma_{\text {ext }}$ to distinguish it from $\mathrm{SpEx} \sigma_{\text {ext }}$ ) averaged over the $\mathrm{SpEx}$ 
sampling intervals (see Sect. 2.2) were compared to the 450 , 532, and $632 \mathrm{~nm}$ channels of SpEx (Fig. 3). Excellent agreement was found with slopes of $1.020 \pm 0.002,0.998 \pm 0.003$, and $1.057 \pm 0.004$ for all of the data in each of the three channels (gray plus markers in Fig. 3), respectively. Three intervals were used to look at mean comparisons: $15 \mathrm{~min}$ (light colored circles), $30 \mathrm{~min}$ (dark colored triangles), and $60 \mathrm{~min}$ (black diamonds). The slopes, intercepts, and $r^{2}$ values for all of the fits are shown in Fig. 3. These fits were performed using data limited to the valid measurement range (i.e., above the lower limit of detection, LLOD). Tests indicated that a limit of twice the measurement uncertainty provided a suitable $\operatorname{LLOD}\left(10 \mathrm{Mm}^{-1}\right)$.

The SpEx data were more variable than the NT $\sigma_{\text {ext }}$ as is evident in time series comparisons throughout the cruise (Fig. 4a and Figs. S6 and S7, top panel). This is partly attributable to the differing noise characteristics of the measurement techniques, but it also arises from differences in sampling intervals where the standard error of the means reduces the variability by the square root of the number of samples in the mean. The NT $\sigma_{\text {ext }}$ represent 30 s means calculated from $\sim 10 \mathrm{~s} \sigma_{\text {scat }}$ and $1 \mathrm{~s} \sigma_{\text {abs }}$ measurements for each $\mathrm{SpEx}$ $\sigma_{\text {ext }}$ spectrum. Averaging SpEx $\sigma_{\text {ext }}$ reduces the variability (Fig. 4b and Figs. S6 and S7, middle panel) according to the standard error of the means. However, not all of the variability evident in Fig. 4 is noise. Limiting the data range in the time series to $2 \mathrm{~d}$ (Fig. 5) illustrates that the native resolution of $\mathrm{SpEx}$ captured rapid changes that were also evident in the NT data. For example, consider the double peak feature that occurred around 03:00 on 25 May (Fig. 5a). This temporal variation is lost even in the $15 \mathrm{~min}$ average (Fig. 5b).

For clarity, the SDs for the means are shown separately (Fig. 4c and Figs. S6 and S7, bottom panel). Most of the SDs of the means in these channels were consistent with the measurement error of about $\pm 5 \mathrm{Mm}^{-1}$ with larger values arising from changes in the ambient conditions. Hence, the SDs of the 60 min means describe an upper envelope compared to the 15 and 30 min means as changing ambient conditions led to greater variability in the means. Together, the results shown in Figs. 3-5 show that quantitative data were obtained under field conditions with SpEx at its native sampling resolution.

\subsection{Evaluating extinction Ångström exponents $\left(\alpha_{\text {ext }}\right)$ with hyperspectral extinction data}

With the spectral data available from SpEx, it was possible to test the power law behavior of the individual and mean spectra by fitting a line to each spectrum in logarithmic space per Eq. (2), where the Ångström exponent, $\alpha_{\text {ext }}$, is the negative value of the slope. As discussed in the introduction, if a power law described the relationship well, $\alpha_{\text {ext }}$ should be invariant with wavelength. Yet clear separation was found in $\alpha_{\text {ext }}$ from linear fits to all of the individual spectra (all data, Fig. 6a) depending on the wavelength range used for the fit.
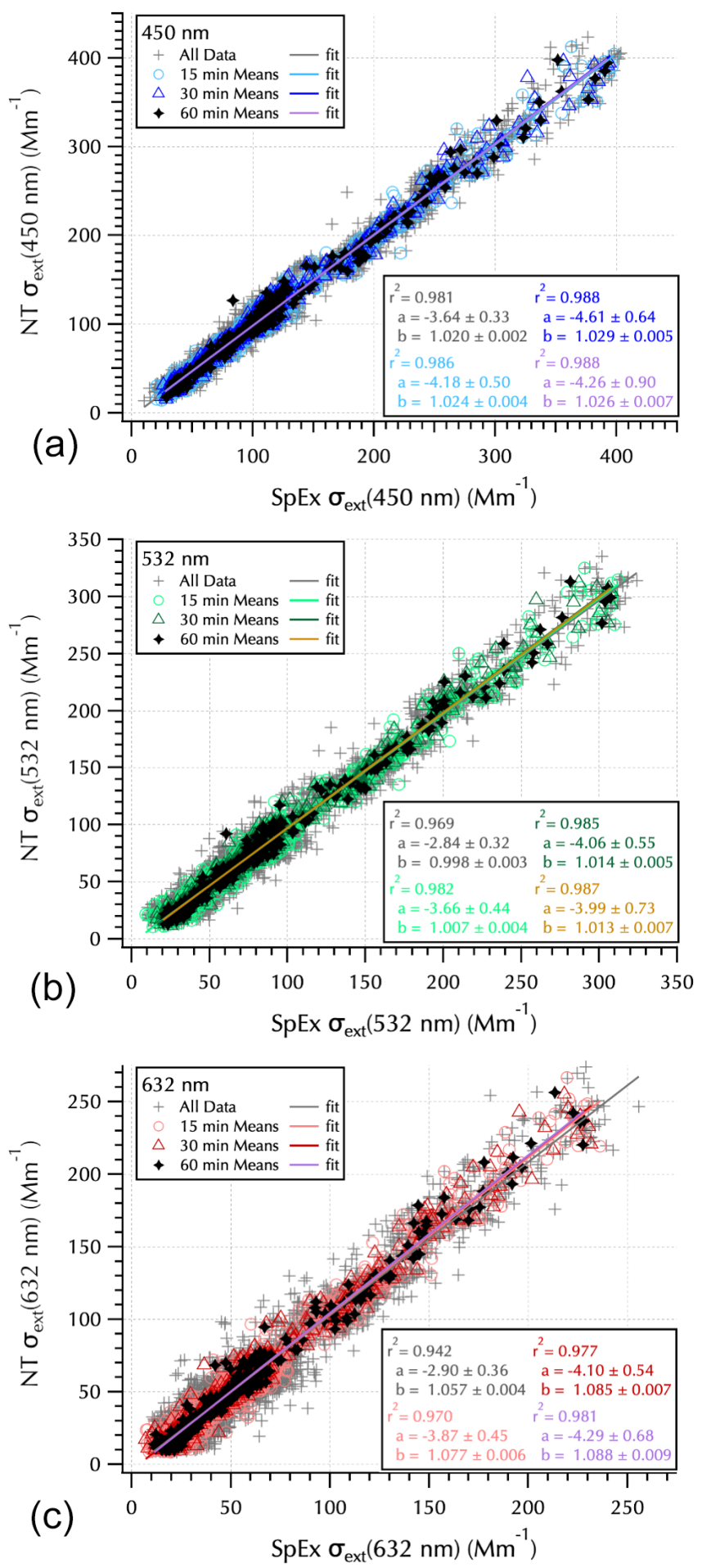

Figure 3. NT vs. SpEx $\sigma_{\text {ext }}(450 \mathrm{~nm}, \mathbf{a} ; 532 \mathrm{~nm}, \mathbf{b} ; 632 \mathrm{~nm}, \mathbf{c})$. All data points (gray pluses) are shown with $15 \mathrm{~min}$ (light colored circles), $30 \mathrm{~min}$ (dark colored triangles), and $60 \mathrm{~min}$ (black symbols) means. Fit lines, coefficients, and $r^{2}$ values are color-coordinated with the symbols, except for the black markers where the fit lines used a light color for visibility. Above LLOD points only. 


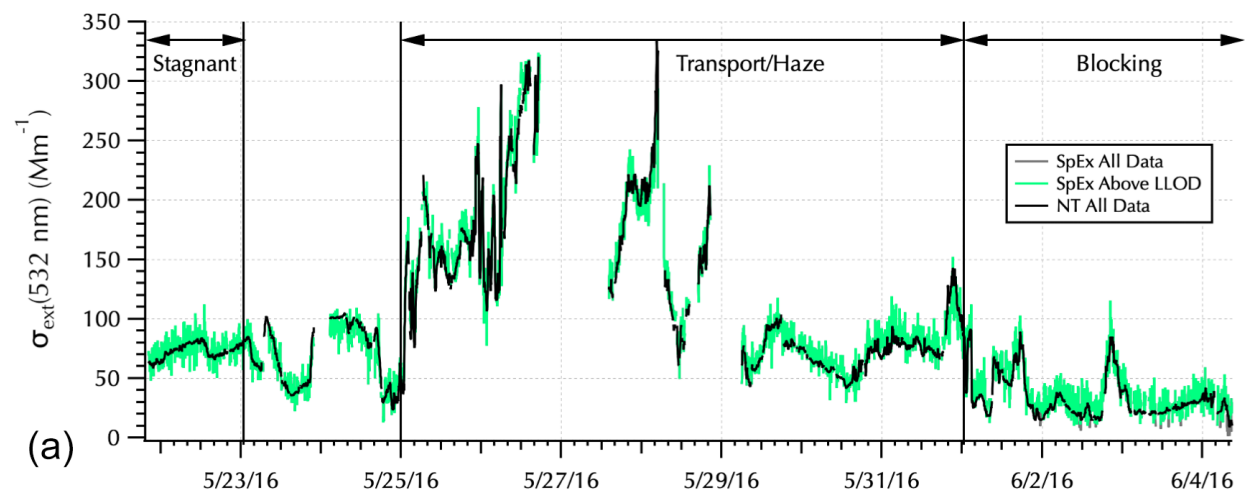

Date \& Time (KST)

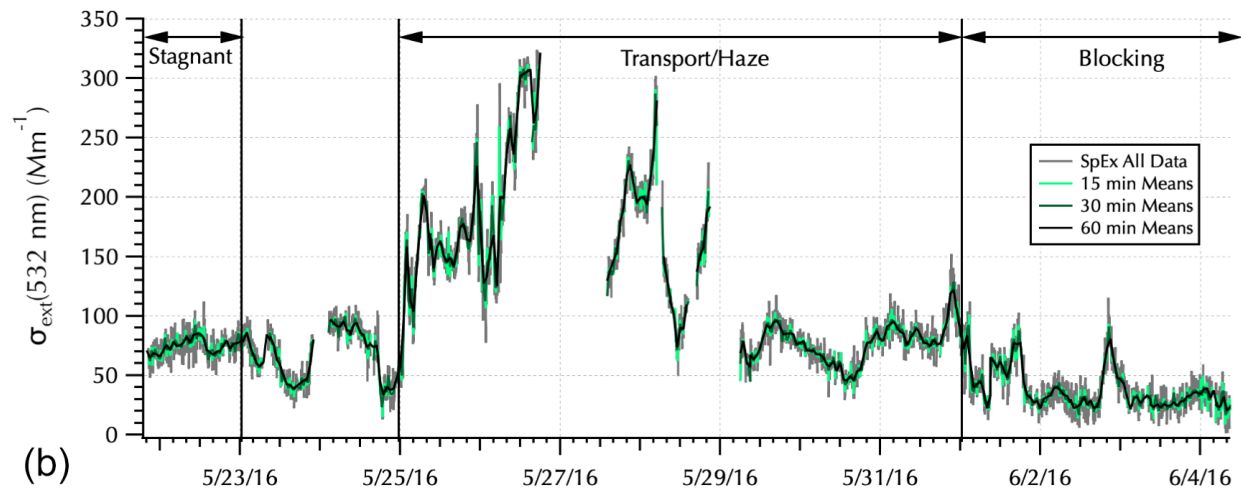

Date \& Time (KST)

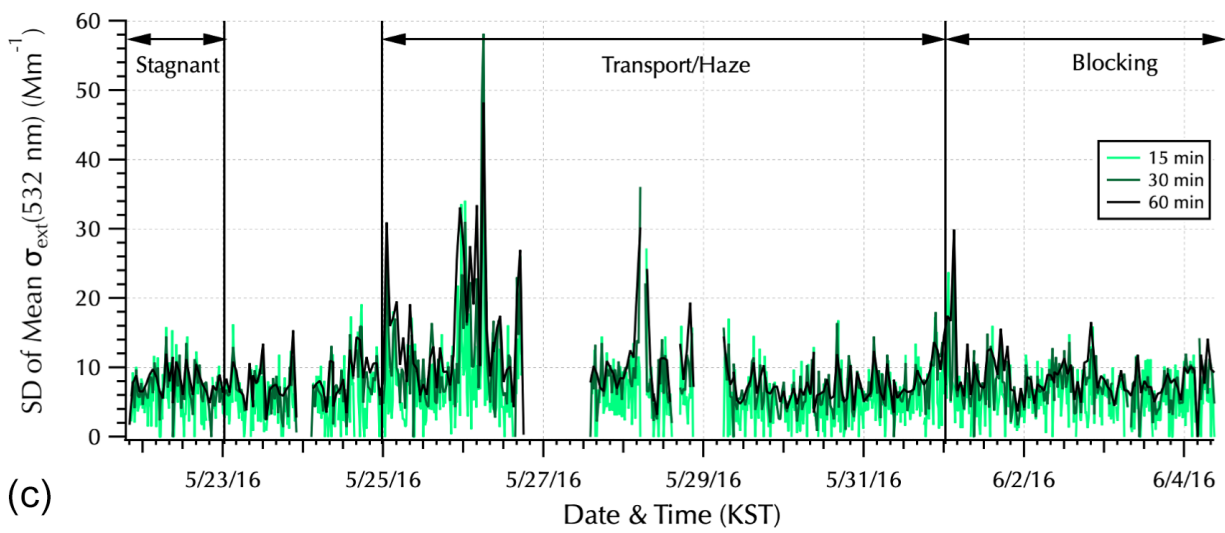

Figure 4. Time series of $532 \mathrm{~nm} \sigma_{\text {ext }}\left(\mathrm{Mm}^{-1}\right)$ throughout the cruise. (a) SpEx (all data, gray; above LLOD, green; these curves are coincident until 2 June when the lowest values are below detection and hence appear gray) with NT $\sigma_{\text {ext }}$ (black). (b) SpEx (all data, gray) with 15 min (light green), $30 \mathrm{~min}$ (dark green), and $60 \mathrm{~min}$ (black) means. (c) SpEx SDs of the $15 \mathrm{~min}$ (light green), $30 \mathrm{~min}$ (dark green), and $60 \mathrm{~min}$ (black) means. Meteorological periods shown as in Fig. 2.

The $\alpha_{\text {ext }}$ from fits to the full range (300-700 nm) and two partial ranges $(450-532 \mathrm{~nm})$ and $(532-632 \mathrm{~nm})$ deviate from the $1: 1$ line expected when plotted vs. $\alpha_{\text {ext }}$ from fits to the $450-632 \mathrm{~nm}$ range. This result was also found for $\alpha_{\text {ext }}$ determined from all of the mean spectra sets as well (e.g., those from the 30 min mean spectra, Fig. 6b).

Most of the SpEx spectra measured during the cruise exhibited curvature over the $300-700 \mathrm{~nm}$ range in logarithmic space. Note that in order to compare results here to previously published work (Sect. 4), for the remainder of this section fits will be shown using wavelength in units of micrometers $(\mu \mathrm{m})$. This change in units does not alter the values of $\alpha_{\text {ext }}$ (which are invariant with wavelength, and hence the choice of units does not matter), but it does change the other coefficients from the mathematical fits to the spectra as will be discussed further in Sect. 4. An example of the observed curvature is provided in Fig. 7. The measured spectrum shown (red curve, Fig. 7a-f) is curved such that residuals (the difference between the measured spectrum and the mathematical fit, blue curves) from the linear fits (black lines, 

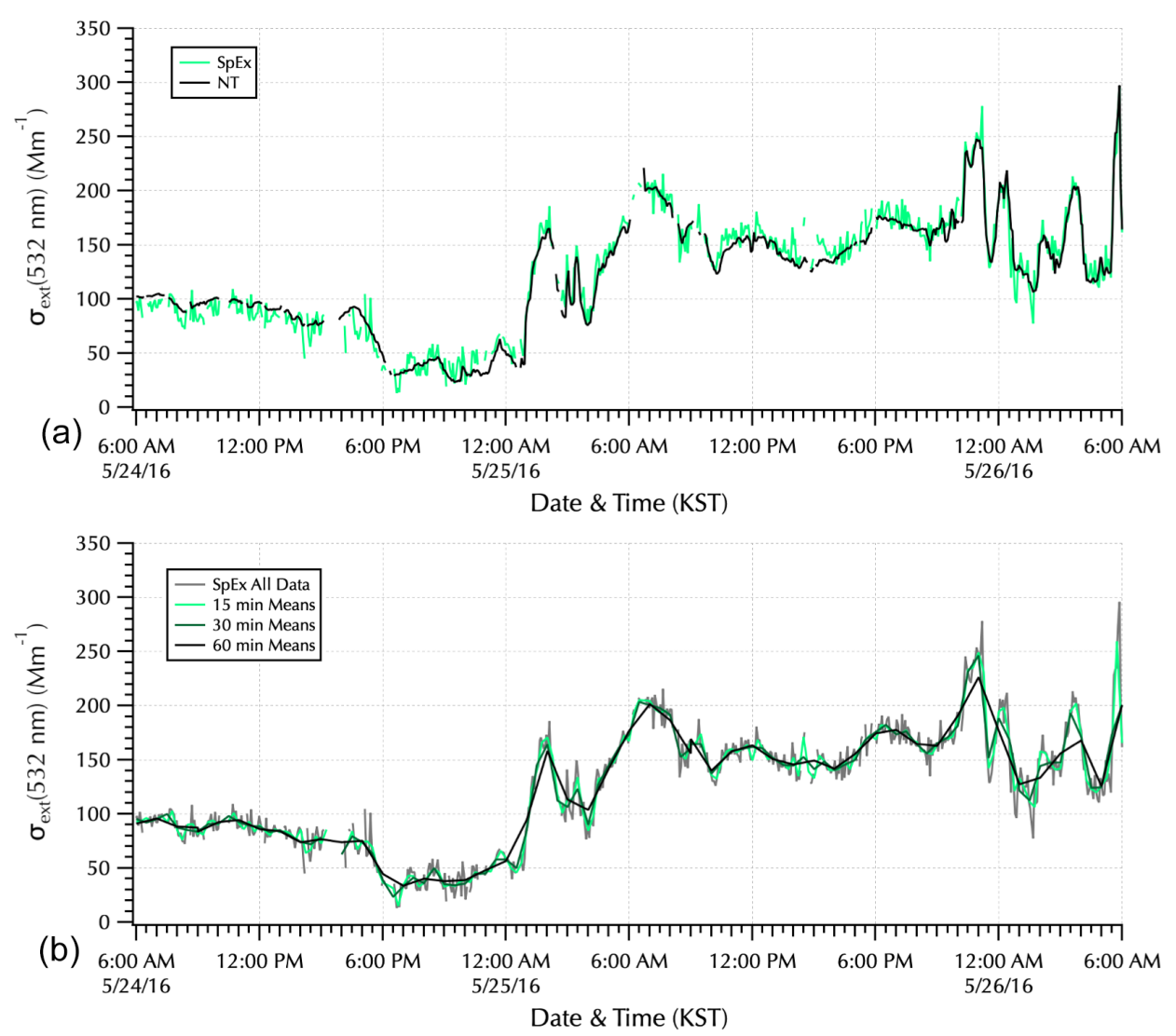

Figure 5. Two day highlight of the top two panels of Fig. 4. (a) $\sigma_{\text {ext }}(532 \mathrm{~nm})$ from SpEx (green) shown with NT (black). (b) $\sigma_{\text {ext }}(532 \mathrm{~nm})$ from $\mathrm{SpEx}$ (all data, gray) with $15 \mathrm{~min}$ (light green), $30 \mathrm{~min}$ (dark green), and $60 \mathrm{~min}$ (black) means.
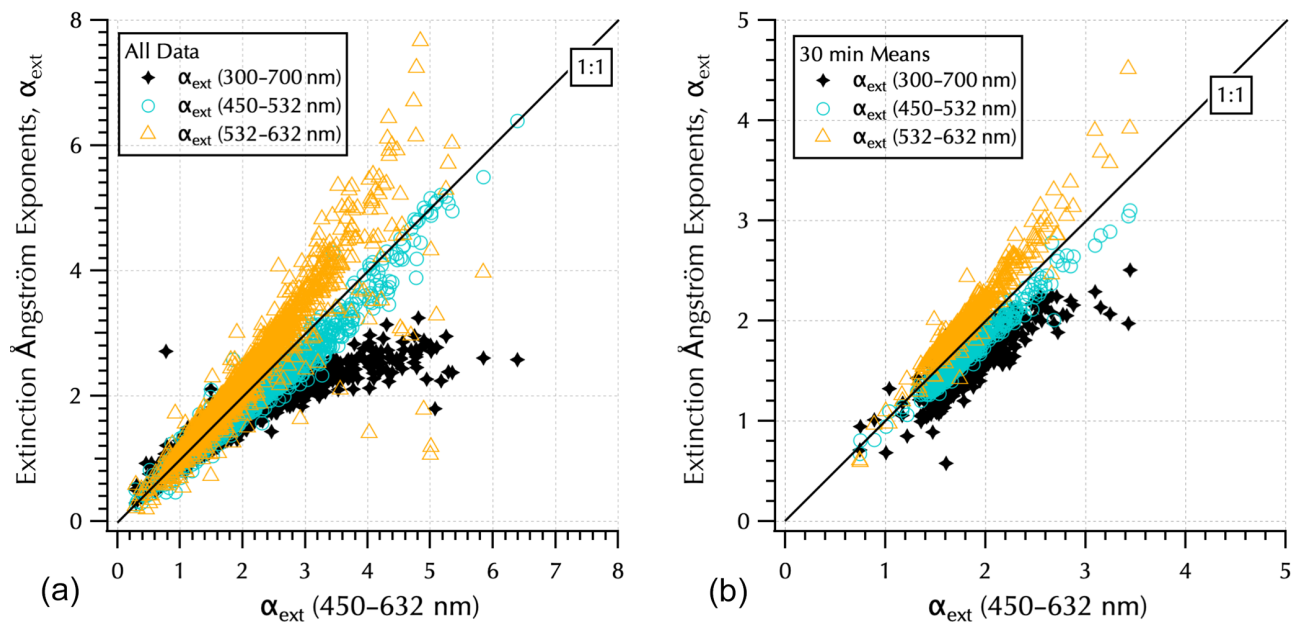

Figure 6. $\alpha_{\text {ext }}$ determined over three different wavelength ranges (300-700 nm, black diamonds; 450-532 nm, teal circles; and 532-632 nm, gold triangles) compared to that found over the 450-632 nm range ( $x$ axis). All data (a) and 30 min means (b).

Fig. 7a, b and c) are also curved. If a particular mathematical function (here, a power law) provides a good fit to the data, the residuals should be randomly distributed around zero. If there is a trend (the curvature evident here), then other functions should be considered to see if a better fit may be obtained. The curvature in the residuals is evident not only across the full wavelength range (Fig. 7c), but for subsets of that range as well (e.g., the $0.45-0.632 \mu \mathrm{m}$ fit, Fig. 7a). Note that the log scale used to plot the spectrum (red curves) in Fig. 7 along with the relatively small ex- 
tinctions at long wavelengths exaggerates the appearance of noise at those wavelengths (i.e., $\pm 5 \mathrm{Mm}^{-1}$ at the red end where $\sigma_{\text {ext }} \sim 20 \mathrm{Mm}^{-1}, \mathrm{LN}(20) \sim 3$, is more obvious than in the UV where $\sigma_{\text {ext }} \sim 150 \mathrm{Mm}^{-1}, \mathrm{LN}(150) \sim 5$ ). Nonetheless, the intensity of the xenon lamp decreases from 600 to $700 \mathrm{~nm}$ (Fig. S5; in Fig. 7, $\mathrm{LN}(0.6 \mu \mathrm{m}) \sim-0.51, \mathrm{LN}(0.7 \mu \mathrm{m})$ $\sim-0.36$ ) such that smaller values of $I_{0}$ combined with the small differences between $I$ and $I_{0}$ in this wavelength range lead to slightly greater uncertainty in $\sigma_{\text {ext }}$ (Eq. 4).

The wavelength-dependent curvature can lead to large errors if used to extrapolate to wavelengths beyond the measured range of values. For example, using $\alpha_{\text {ext }}$ found from the $0.45-0.632$ fit to extrapolate to $0.3 \mu \mathrm{m}$ (Fig. 7b) leads to a value of $\operatorname{LN}\left(\sigma_{\text {ext }}\right)=5.7099$, while the measured value was 5.0839, i.e., an extrapolated extinction of $302 \mathrm{Mm}^{-1}$, $87 \%$ larger than the measured extinction of $161 \mathrm{Mm}^{-1}$. This wavelength is the most extreme, but the positive artifact is present throughout the UV range: with the extrapolated extinction $73 \%$ and $29 \%$ greater at 0.315 and $0.365 \mu \mathrm{m}$, respectively. At $0.45 \mu \mathrm{m}(\mathrm{LN}(0.45 \mu \mathrm{m})=-0.8$, Fig. 7$)$, the lower end of the fit range of values, the fit extinction was $6 \%$ greater than the measured value, while at $0.532 \mu \mathrm{m}$ (the middle of the fit range) it was $3 \%$ less.

Previous work has shown that second-order polynomials in logarithmic space can provide a better fit to ambient aerosol optical depth (AOD, aerosol extinction integrated over an atmospheric column) spectra than power law fits (e.g., Eck et al., 1999, 2001a, b, 2003a, b; Schuster et al., 2006; Kaskaoutis et al., 2010, 2011). In the example shown in Fig. 7, it is clear that a second-order polynomial fit (black curves, Fig. 7d-f) reduces the trends in the residuals both over the full wavelength range (Fig. 7f) and over the 0.45$0.632 \mu \mathrm{m}$ subset of that range (Fig. 7d) from that obtained from the linear fits. The improved fit provided by a secondorder polynomial for all of the measured spectra is shown using histograms of the residuals at six wavelengths across the measured wavelength range (Fig. 8). For both the linear fits (black bars) and the second-order polynomial fits (red bars), the range of values for residuals at each wavelength is divided into 20 bins. The narrower bins for the second-order polynomial fits reflect the smaller range in residual values compared to those from the linear fits. The best agreement between the two sets of residuals shown in Fig. 8 is found at $0.532 \mu \mathrm{m}$, where the linear fit residuals are distributed around zero. At longer and shorter wavelengths, however, the linear residuals tend to be either positive or negative at any given wavelength, while the second-order polynomial fit residuals are centered around zero across all wavelengths. These results confirm that second-order polynomials provide a better fit to the data than linear fits.

Unfortunately, just as extrapolating linear fits beyond the measurement range is problematic, the same is also true for the second-order polynomial fits (Fig. 7e). In this case, at 0.45 and $0.532 \mu \mathrm{m}$ (within the fit range) the fit agrees with the measured extinctions within $1 \%\left(\sim 85\right.$ and $56 \mathrm{Mm}^{-1}$, respectively). However, at increasingly shorter wavelengths the fit diverges from the measured spectrum with the fit values $15 \%, 28 \%$, and $34 \%$ too small at $0.365,0.315$, and $0.3 \mu \mathrm{m}$, respectively. The divergence of either fit from the measured spectrum when extrapolating beyond the fit wavelength range (Fig. 7b and e) highlights the need for measurements across a broad spectral range in order to minimize the need for extrapolation.

\section{Discussion}

The motivation to fit the SpEx spectra with a second-order polynomial came primarily from the work of Schuster et al. (2006) in which both Mie calculations and AERONET data were used to explore the additional information that spectral curvature may provide. A comparison of the coefficients obtained from SpEx to the fine-fraction subset of aerosols reported in Schuster et al. (2006) revealed two key differences between the data sets. First, the $a_{1}$ and $a_{2}$ coefficients spanned a wider range of values than those obtained in the prior work (Fig. 9a). Second, Schuster et al. (2006) reported an empirical approximation such that $\alpha_{\text {ext }}$ was approximately equal to $a_{2}-a_{1}$. This approximation clearly does not hold for the values obtained from this data set (Fig. 9a). These differences can be understood as follows.

The two expressions used here to fit the relationship between $\sigma_{\text {ext }}$ and $\lambda$ are related by their negative derivative, defined as $\alpha$ in Eq. (2). That is, the derivative of the linear fit $(y=a+b x ; \mathrm{d} y / \mathrm{d} x=b)$ equals the derivative of the second-order polynomial fit $\left(y=a_{0}+a_{1} x+a_{2} x^{2} ; \mathrm{d} y / \mathrm{d} x=\right.$ $\left.a_{1}+2 a_{2} x\right)$ such that

$\alpha_{\mathrm{ext}}=-b=-\left(a_{1}+2 a_{2}(\mathrm{LN}(\lambda))\right.$.

Note that the derivative of Eq. (5), $\alpha_{\text {ext }}^{\prime}=$ $-\mathrm{d} \alpha_{\text {ext }} / \mathrm{dLN}(\lambda)=-2 a_{2}$ defines the curvature of the extinction spectra (Eck et al., 1999). For any given spectrum, there is one wavelength at which the linear and second-order polynomial fits yield equivalent results in Eq. (5). This must not be confused with every wavelength measured in the spectrum, so we will refer to this one wavelength as the characteristic wavelength of the measurement range, $\lambda_{\text {ch }}$, from here on. It can be calculated for each measured spectrum from the two sets of fit coefficients for that spectrum. That is, rewriting Eq. (5) in terms of $\lambda_{\text {ch }}$ the characteristic wavelength of the measured spectrum may be calculated from $\lambda_{\mathrm{ch}}=e^{\wedge}\left(\left(\alpha_{\mathrm{ext}}+a_{1}\right) /-2 a_{2}\right)$. For the SpEx data set, $\lambda_{\mathrm{ch}}$ was found to range from $0.36-0.46 \mu \mathrm{m}$. In contrast, the empirical fit of $\alpha_{\text {ext }}=a_{2}-a_{1}$ implies $\lambda_{\text {ch }}$ $\sim 0.61$, i.e., $\operatorname{LN}(0.61) \sim-0.5$. The dependence of Eq. (5) on the characteristic wavelength results in spectra sets with differing $\lambda_{\text {ch }}$ exhibiting different mapping between $\alpha_{\text {ext }}$ and $\left(a_{1}, a_{2}\right)$. To illustrate this, consider the range of $\alpha_{\text {ext }}$ values $(0.29-3.25)$ found from linear fits over $0.3-0.7 \mu \mathrm{m}$ to all of the spectra measured by SpEx during KORUS-OC. This 

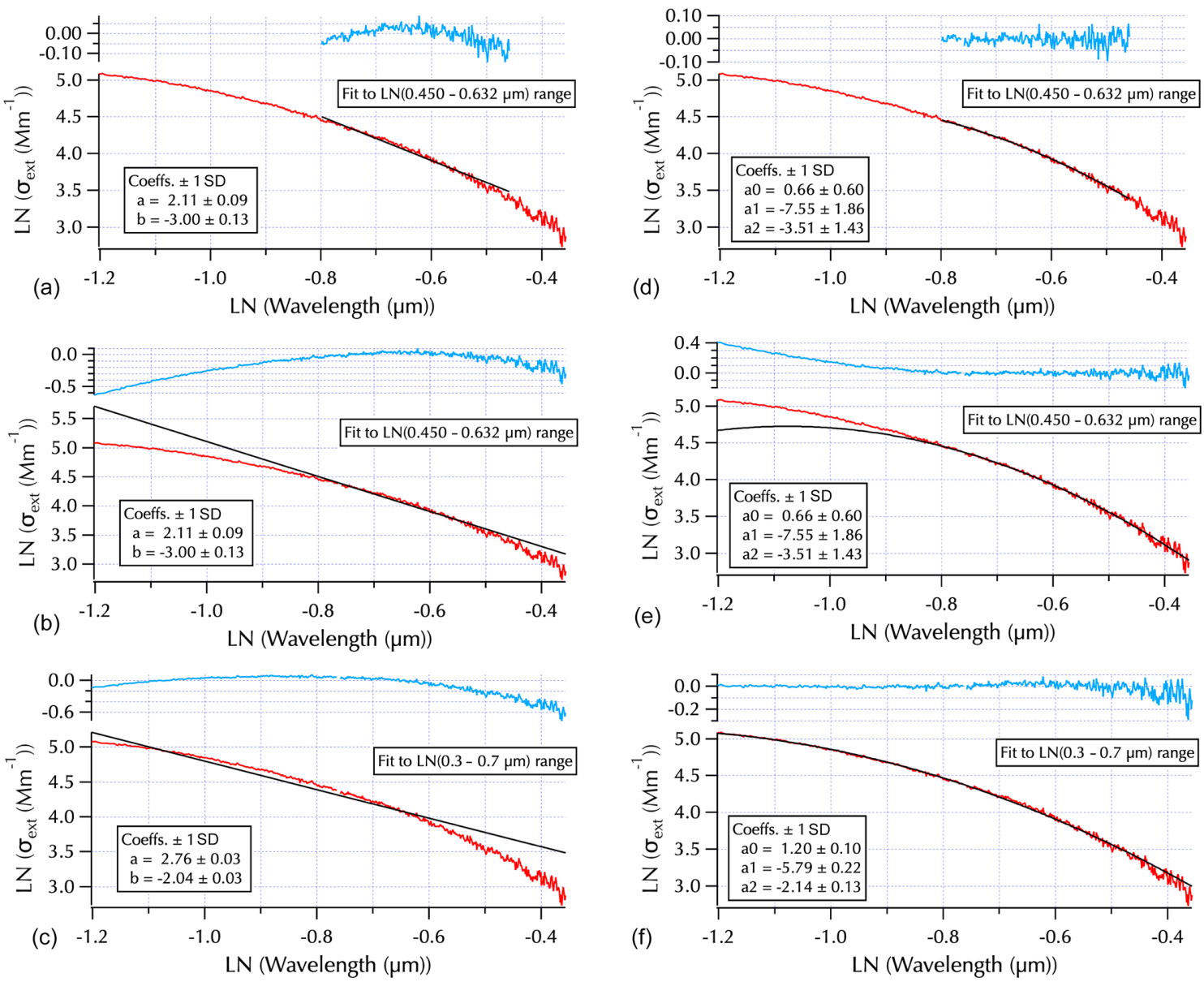

Figure 7. Example of wavelength dependence of $\operatorname{LN}\left(\sigma_{\text {ext }}\left(\mathrm{Mm}^{-1}\right)\right)$ spectra (red curves) as a function of LN(wavelength $\left.(\mu m)\right)$. Linear ( $y=a+b(x)$, a-c; here the intercept $a=\operatorname{LN}(\beta)$, the value of $\operatorname{LN}\left(\sigma_{\text {ext }}\right)$ at $1 \mu \mathrm{m}$ where $\operatorname{LN}(1 \mu \mathrm{m})=0$, and the slope $\left.b=-\alpha\right)$ and secondorder polynomial $\left(y=a_{0}+a_{1}(x)+a_{2}\left(x^{2}\right)\right.$, d-f) fits (black curves) are shown with the fit residuals $\left(=\mathrm{LN}\left(\sigma_{\mathrm{ext}}\left(\mathrm{Mm}^{-1}\right)\right)-\right.$ fit, blue curves $)$. Residuals randomly distributed around zero indicate a good fit by the mathematical function used to fit the data, trends in residuals suggest another function may provide a better fit. Fits to the $\mathrm{LN}(0.450-0.632 \mu \mathrm{m})$ subrange $(\mathbf{a}, \mathbf{d})$ and to the full $\mathrm{range}(\mathrm{LN}(0.3-0.7 \mu \mathrm{m})$, $\mathbf{c}, \mathbf{f})$ are shown. Panels $(\mathbf{b}, \mathbf{e})$ show the extrapolation of the fit in panels $(\mathbf{a}, \mathbf{d})$ over the full measured wavelength range. The $x$ axis labels of -1.2 , $-1.0,-0.8,-0.6$, and -0.4 are the natural $\log$ values for the wavelengths $0.301,0.368,0.449,0.549,0.670$, and $0.698 \mu \mathrm{m}$, respectively, i.e., equal to $\operatorname{LN}(\lambda(\mu \mathrm{m}))$.

range of $\alpha_{\text {ext }}$ values maps differently into $\left(a_{1}, a_{2}\right)$ space as a function of $\lambda_{\text {ch }}$ (Fig. 9b).

There are two special cases evident in Eq. (5) that result in $\alpha_{\text {ext }}=a_{1}$. First, when there is no curvature $\left(a_{2}=\right.$ $0), a_{1}$ describes the same linear fit as $\alpha_{\text {ext }}$. Second, when $\lambda_{\text {ch }}=1 \mu \mathrm{m}$ (i.e., $\mathrm{LN}(1)=0$ ) Eq. (5) is insensitive to curvature such that $a_{2}$ can have any value at all. This can be understood from Eq. (1), where $\alpha$ can be any value when $\lambda=1 \mu \mathrm{m}$ and $p(1 \mu \mathrm{m})$ will always $=\beta$. The former leads to all $\lambda_{\text {ch }}$ sets overlapping at $a_{2}=0$, while the latter exhibits a broad vertical band independent of curvature $\left(a_{2}\right)$ (Fig. 9b). These special cases have important implications. As $\lambda_{\text {ch }}$ approaches $1 \mu \mathrm{m}$ the measurement becomes insensitive to curvature, while at the short wavelengths of light represented by $\lambda_{\text {ch }}<0.1 \mu \mathrm{m}$ the curvature itself becomes unimportant. Hence, to probe spectral curvature Fig. 9b shows measure- ment techniques with $\lambda_{\text {ch }} \sim 0.5 \pm 0.2 \mu \mathrm{m}$ provide the greatest sensitivity with sufficient separation in $\left(a_{1}, a_{2}\right)$ to distinguish aerosol microphysical and chemical properties influencing the spectral shape.

The rotation as a function of $\lambda_{\text {ch }}$ shown in Fig. 9 also illustrates why wavelength units of micrometers $(\mu \mathrm{m})$ must be used to calculate $\left(a_{1}, a_{2}\right)$. As $\lambda_{\text {ch }}$ increases to values $>1 \mu \mathrm{m}$, the $\alpha$ map rotates clockwise (Fig. S8). If one used $\lambda_{\text {ch }}=410 \mathrm{~nm}$ rather than $0.41 \mu \mathrm{m}$, it would map into a narrow band in the next quadrant of $\left(a_{1}, a_{2}\right)$ space spanning a wide range in $a_{1}$ but a narrow range in $a_{2}$, resulting in little curvature sensitivity. The calculation of $\alpha_{\text {ext }}$ is wavelength independent and will produce the same result no matter what units are used. This is not the case for the calculation of $\left(a_{1}, a_{2}\right)$, so it must be emphasized that for curvature the units matter. 

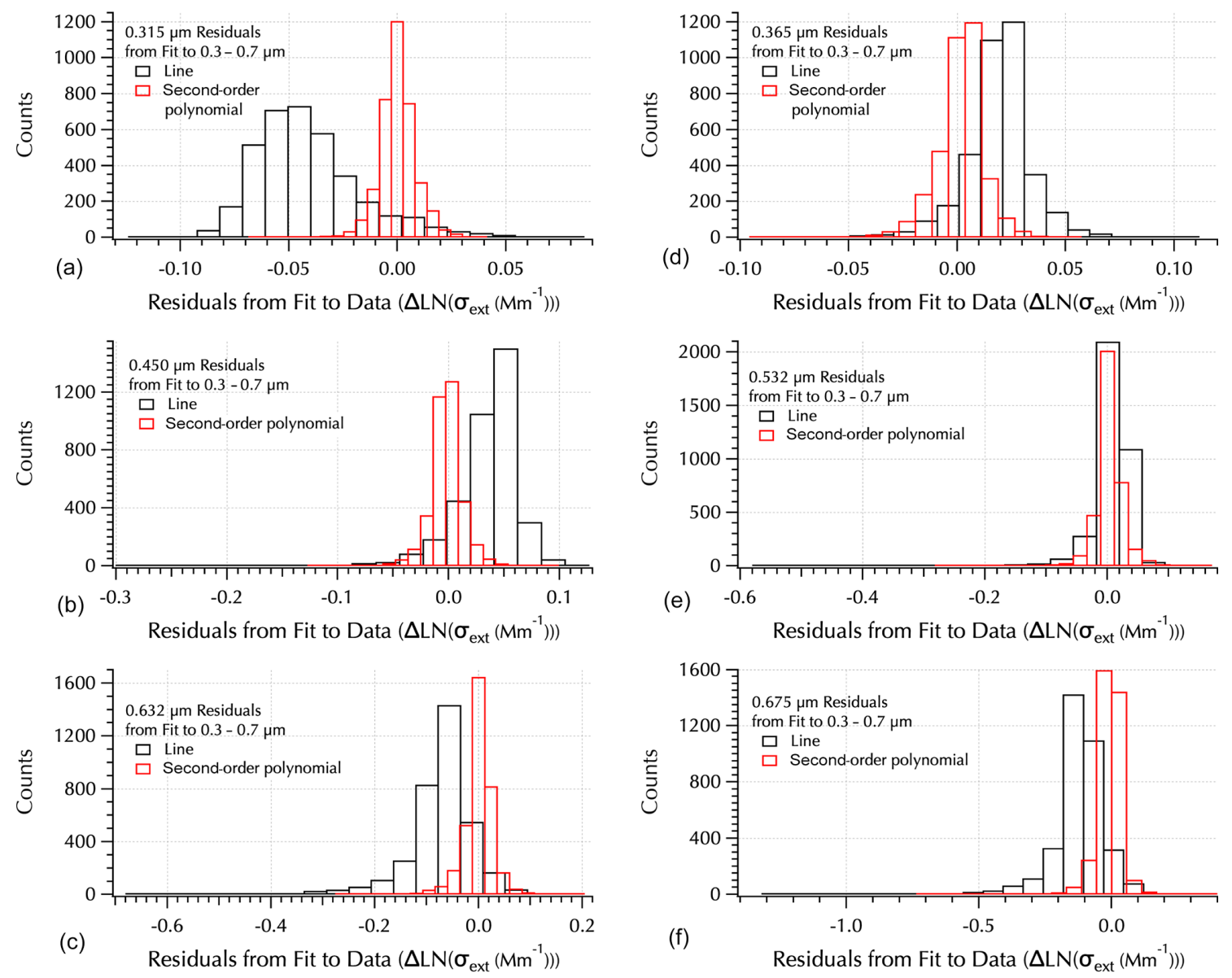

Figure 8. Comparison of residuals (the difference between the data and mathematical function fit to that data) from a line fit (black) and second-order polynomial fit (red) to the measured $\operatorname{LN}\left(\sigma_{\text {ext }}\left(\mathrm{Mm}^{-1}\right)\right.$ ) spectra over the $0.3-0.7 \mu \mathrm{m}$ range for six wavelengths: 0.315 (a), 0.365 (d), 0.45 (b), 0.532 (e), 0.632 (c), and $0.675 \mu \mathrm{m}(\mathbf{f})$.

The angular difference between $\lambda_{\text {ch }}=0.61$ and $0.41 \mu \mathrm{m}$ accounts for the shift between the mapping reported in Schuster et al. (2006) and this work. The differing values in $\lambda_{\text {ch }}$ arise from the different spectral ranges between AERONET (seven bands spanning 0.34-1.02 $\mu \mathrm{m}$, Schuster et al., 2006) vs. $0.3-0.7 \mu \mathrm{m}$ for $\mathrm{SpEx}$. The $\alpha_{\text {ext }}$ values from fits to the spectra set map into the expected bands (Fig. 9c) with the color distribution shifting slightly over the range of calculated $\lambda_{\text {ch }}=0.36-0.46 \mu \mathrm{m}$. Note that the most extreme values in $a_{1}$ for the KORUS-OC data set are related to shorter $\lambda_{\text {ch }}$ than the rest of the data set.

Schuster et al. (2006) used this type of coefficient mapping to distinguish different aerosol size distributions via curvature that otherwise exhibit the same $\alpha$. In particular, while fine-mode aerosols exhibit negative curvature, the presence of sufficient coarse-mode aerosols in a bimodal size distribution induces positive curvature due to the efficient extinction of light at longer wavelengths by larger particles. Here, the inlet limited the size range of sampled aerosol to the submicron fraction, such that positive curvature is not ex- pected. Aerosol size distributions were not measured aboard ship during the cruise, but as described in Sect. 3.1, previously published work provides sufficient information for a broad characterization of the different ambient aerosol populations prevalent during the three meteorological regimes that occurred during KORUS-OC. This context is used to assess the mapping of SpEx data into $\left(a_{1}, a_{2}\right)$ space. For clarity, the 60 min mean spectra data are used (Fig. 10).

In addition to the evident separation in $\alpha_{\text {ext }}$ across $\left(a_{1}, a_{2}\right)$ space (Figs. 9 and 10a) there is also clear separation as a function of aerosol loading using $\sigma_{\text {ext }}(0.532 \mu \mathrm{m})$ as a proxy for ambient aerosol concentrations (Fig. 10c). High concentrations $\left(\sigma_{\text {ext }}(0.532 \mu \mathrm{m})>150 \mathrm{Mm}^{-1}\right)$ exhibit a relatively small range of $a_{1}$ and $a_{2}$ values. Generally, these spectra exhibit the greatest curvature (i.e., largest absolute values of $a_{2}$ for any given $a_{1}$ ). In contrast, low concentrations $\left(\sigma_{\text {ext }}(0.532 \mu \mathrm{m})<75 \mathrm{Mm}^{-1}\right)$ span a wide range of values in $a_{1}$ and $a_{2}$. As described in Sect. 3.1 there were three distinct meteorological regimes during the cruise (Peterson et al., 2019) that led to different ambient aerosol popula- 
(a)
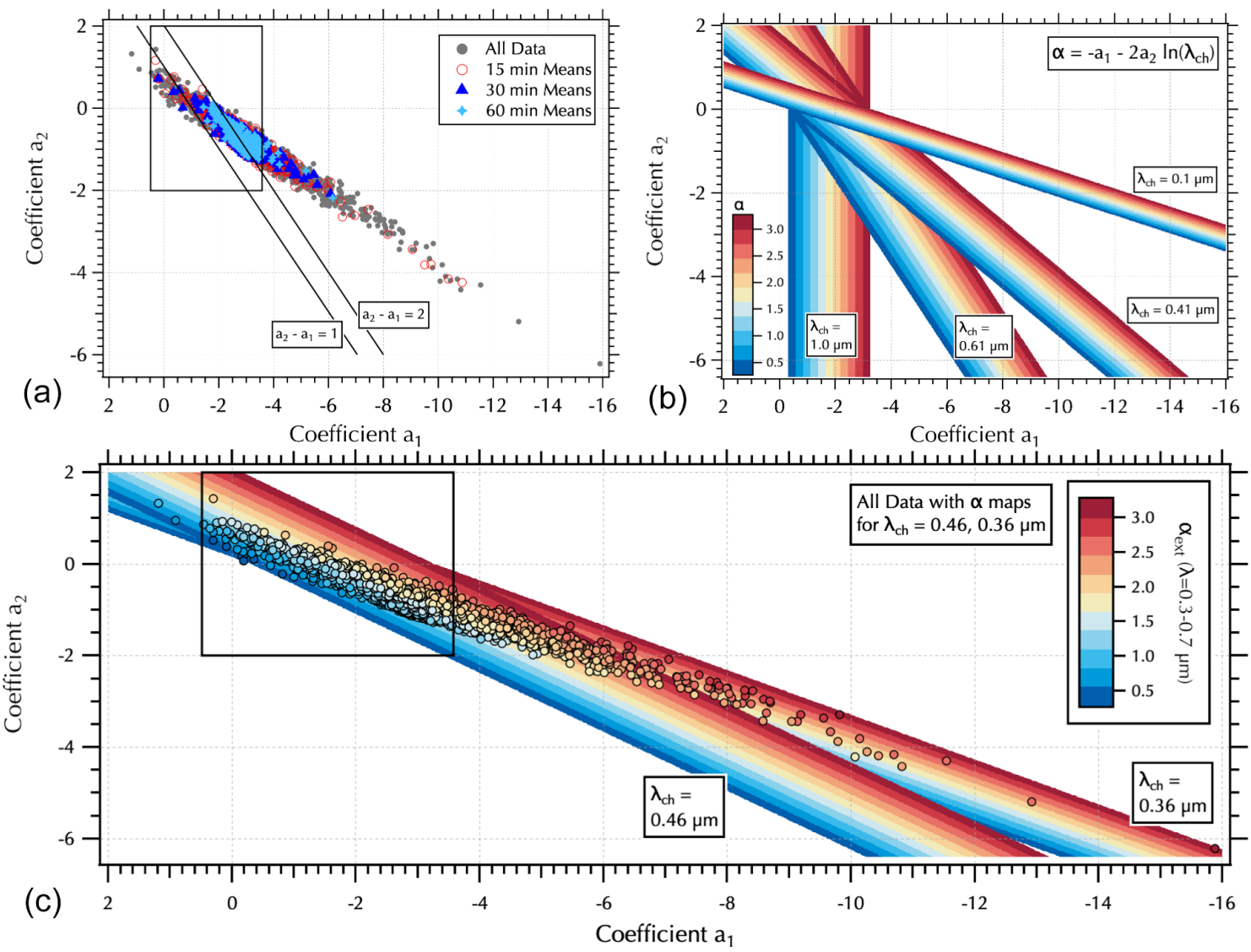

Figure 9. (a) Coefficients $a_{2}$ vs. $a_{1}$ from second-order polynomial fits to the full wavelength range $(0.3-0.7 \mu \mathrm{m})$ of the individual (all data, gray filled circles) and mean ( $15 \mathrm{~min}$, red open circles; $30 \mathrm{~min}$, dark blue triangles; and $60 \mathrm{~min}$, light blue diamonds, average) spectra. The black box shows the limits of the Schuster et al. (2006) Fig. 6 plot; black lines show approximate equivalents to $\alpha_{\text {ext }}=1$ and 2 from that work. (b) $\alpha$ mapped into $\left(a_{1}, a_{2}\right)$ space as a function of the characteristic wavelength $\left(\lambda_{\mathrm{ch}}\right)$ of the measured spectral range. (c) $\alpha_{\text {ext }}$ calculated from the full spectral range of SpEx (colored dots) overlaid on $\alpha$ maps that cover the range of $\lambda_{\text {ch }}$ values calculated from the data set. The black box is the same as the one in panel (a).

tions. Hence, the separation in aerosol loading should not be viewed as a function of loading for a uniform aerosol population but rather as an artifact of the differing size distributions and, to a lesser extent, composition.

The $\left(a_{1}, a_{2}\right)$ map separated according to the defined meteorological regimes reveals strikingly different distributions for the three periods (Fig. 10b). The spectra during the Stagnant period (predominantly submicron aerosols, where $\mathrm{PM}_{2.5} \sim \mathrm{PM}_{1}$, Jordan et al., 2020, dominated by locally produced SOA, Kim et al., 2018; Nault et al., 2018; Peterson et al., 2019; Choi et al., 2019; Jordan et al., 2020) produced a remarkably narrow range of $a_{1}$ and $a_{2}$ values that essentially lie along a single $\alpha_{\text {ext }}$ line $(\sim 1.5)$ for the 60 min mean spectra set. In contrast, the spectra during the Blocking period (likely small absorbing aerosols from relatively fresh ship emissions) exhibit a wide range in $a_{1}$ and $a_{2}$ values with values of $\alpha_{\text {ext }}$ generally $>1.6$. However, $\alpha_{\text {ext }}$ values for this group also span the full range of observed $\alpha_{\text {ext }}$ primarily when the absolute value of $a_{2}$ was small $(\leq|-0.6|)$. The large variability of this group may be due in part to the low extinctions where the sensitivity of $\alpha_{\text {ext }}$ to uncertainty in $\sigma_{\text {ext }}$ is greatest. It may also reflect the heterogeneity of aerosol sources encountered in the marine boundary layer as the ship cruised around the West Sea during this period.

Finally, the period when aerosol concentrations were highest, Transport/Haze, exhibits the same range in $a_{1}$ as the Stagnant aerosols but with greater curvature (i.e., larger absolute values of $a_{2}$, Fig. 10b). During this period the meteorological conditions that transported polluted air masses eastward from China also created conditions that promoted rapid secondary inorganic aerosol production locally over the S. Korean peninsula (Peterson et al., 2019; Eck et al., 2020; Jordan et al., 2020) that resulted in the growth of fine-mode aerosols to larger sizes $\left(\mathrm{PM}_{2.5}>\mathrm{PM}_{1}\right.$, Eck et al., 2020; Jordan et al., 2020) than observed during the Stagnant period. During the first half of the Transport/Haze period the ship was downwind of S. Korea in the East Sea, while during the second half it was upwind in the West Sea. Splitting the data 

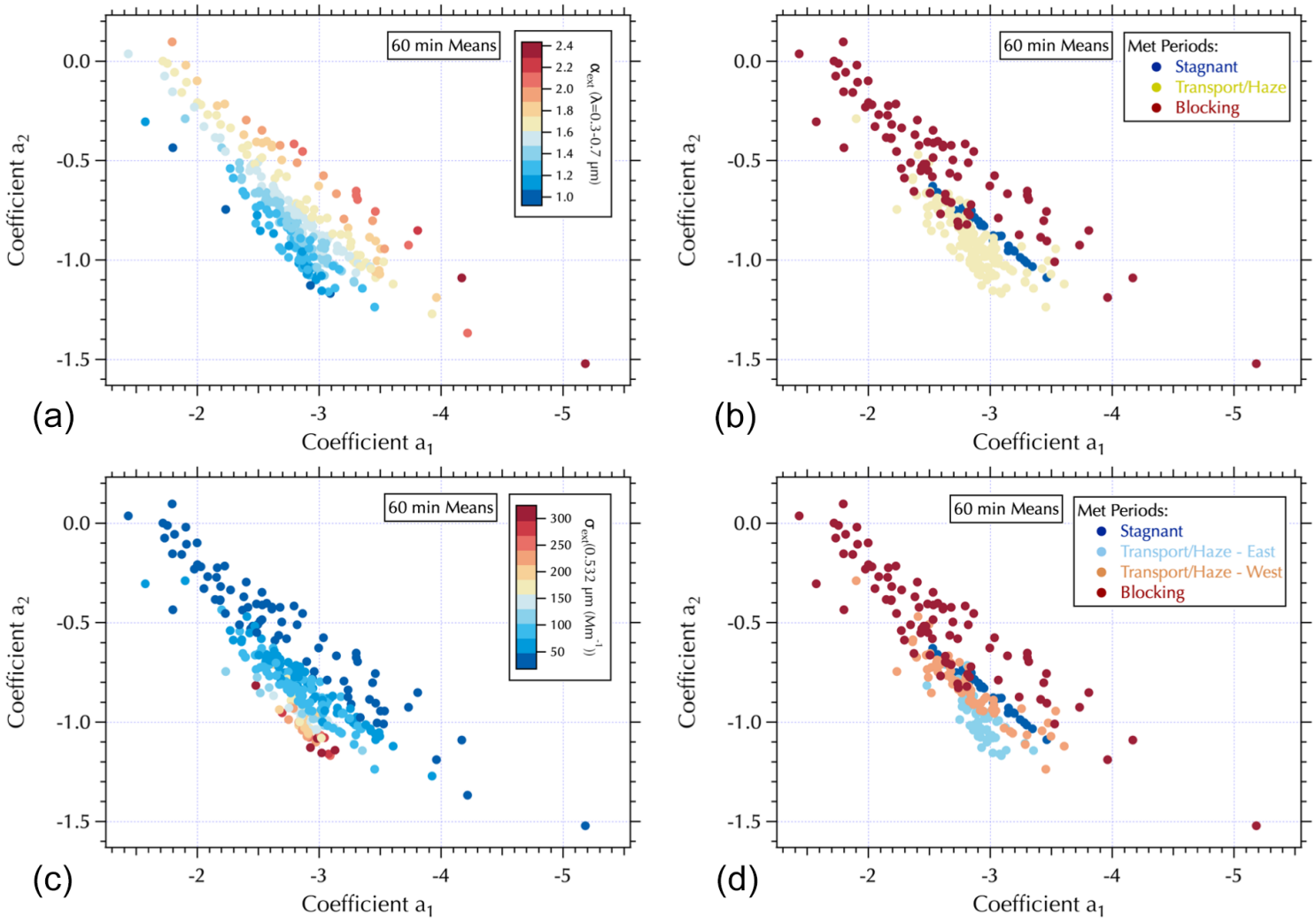

Figure 10. Coefficients $a_{2}$ vs. $a_{1}$ from second-order polynomial fits to the full wavelength range $(0.3-0.7 \mu \mathrm{m})$ of the $60 \mathrm{~min}$ mean spectra colored by $\alpha_{\text {ext }}(\lambda=0.3-0.7 \mu \mathrm{m})(\mathbf{a}), \sigma_{\text {ext }}(0.532 \mu \mathrm{m})\left(\mathrm{Mm}^{-1}\right)(\mathbf{c})$, and the defined meteorological periods described in Peterson et al. (2019) (b) (i.e., excluding the interval when the meteorological regime was in transition, 23 and 24 May, and hence undefined). Panel (d) is the same as panel (b) but with the Transport/Haze samples split between those measured to the east (25-27 May) and west (29-31 May) of the peninsula, excluding those samples collected in transit between the two.

from this period to reflect the position of the ship (Fig. 10d) shows that the highest concentrations of aerosols were observed downwind of S. Korea and exhibited the greatest curvature and the lowest $\alpha_{\text {ext }}$. This result indicates larger particle sizes were present downwind than upwind, consistent with the reported changes in aerosol size distribution due to local production over the Korean peninsula (Eck et al., 2020; Jordan et al., 2020). The upwind distribution resembles the narrow Stagnant distribution in $\left(a_{1}, a_{2}\right)$ space but shifted to a slightly lower $\alpha_{\text {ext }}$.

It is interesting to contrast the range in curvature between the three periods. As shown in Fig. 6, $\alpha_{\text {ext }}$ decreases as the fit range is extended to shorter wavelengths. This is due to the curvature evident in the UV range of Fig. 7 which is not adequately captured by fits to the longer wavelength subranges. In that instance (an individual spectrum from the Stagnant period), $\alpha_{\text {ext }}(0.45-0.632 \mu \mathrm{m})=3$, whereas $\alpha_{\text {ext }}(0.3-0.7 \mu \mathrm{m})=2.04$. The greatest curvature tends to be found for the period with the largest particles observed during the campaign, while for the period when the particles were likely to be smallest, the UV curvature is small or absent, leading to larger $\alpha_{\text {ext }}$ values (Fig. 10). In addition, the largest absolute values of $a_{1}(\geq|-6|)$ found in the individual spectra (Fig. 9) arise from partial spectra where the longer wavelengths of a measured spectrum are below detection. Spectral fits were limited to only above-detection portions of the measured spectrum. This is why the $\lambda_{\text {ch }}$ values for these spectra shift to shorter wavelengths. These spectra are those for which scattering and extinction were observed to be low; hence, the spectral fit is subject to greater uncertainty. This accounts for the finding that some of the finefraction Blocking period aerosols exhibit curvature as large as the other two periods, as well as the limited negative curvature $\left(a_{2} \leq|-0.5|\right)$ and, in a few cases, slightly positive curvature $\left(a_{2} \geq 0\right.$, Figs. 9 and 10). Note that partial spectra are not suitable for retrievals (i.e., comparable to those from AERONET Level 2 data where at a minimum abovedetection values must be available from at least the 0.38 , 0.50 , and $0.87 \mu \mathrm{m}$ channels to ensure nonlinearity in the spectrum is adequately represented). However, partial spectra can be valuable for other analyses such as when combined with absorption coefficients in the calculation of $\omega(\lambda)$ to look for structure in the above-detection range for $\mathrm{SpEx}$, particularly 
in the UV (see Part 2, Jordan et al., 2021). Hence, partial spectra data are not discarded from further examination.

\section{Conclusions}

This work, Part 1 of 2, examined the high-temporalresolution data set (IN101, TAP, and SpEx) collected as part of the in situ aerosol measurement suite deployed aboard the R/V Onnuri for the KORUS-OC cruise. IN101 scattering $\left(\sigma_{\text {scat }}\right)$ and TAP absorption $\left(\sigma_{\text {abs }}\right)$ coefficients were measured at three visible wavelengths throughout the cruise, with single-scattering albedo $(\omega)$ calculated from them. These data were presented to provide an overview of the in situ aerosol measurements throughout the cruise within the context of the prevalent meteorological regimes previously reported for the KORUS-AQ field campaign (Peterson et al., 2019; Jordan et al., 2020). The cruise took place during three distinct meteorological periods where (1) stagnant conditions fostered local (S. Korean) production of secondary organic aerosol, (2) transport from China coupled with local overcast and humid hazy conditions led to secondary production of inorganic aerosol with rapid growth of fine-mode aerosols to larger particle sizes, and (3) a blocking period with limited transport following a frontal passage dramatically reduced aerosol concentrations. Results presented here suggest the aerosols observed aboard R/V Onnuri during this final period were likely relatively fresh small particles from ship emissions into the marine boundary layer. The largest values of $\sigma_{\text {scat }}$ and $\sigma_{\text {abs }}$ were observed when the ship was downwind of the Korean peninsula in the East Sea during the Transport/Haze period. The smallest values of $\omega$ were found when the ship was upwind of the peninsula in the West Sea, with low values arising from reductions in scattering rather than increases in absorption.

Extinction coefficients $\left(\sigma_{\text {ext }}\right)$ calculated from the three visible wavelength $\sigma_{\text {scat }}$ and $\sigma_{\text {abs }}$ data were used to evaluate the performance of $\mathrm{SpEx}$ under field conditions that offered a wide range of concentrations, particles sizes, and composition. Excellent agreement was found for all three wavelengths with slopes equal to $1.020 \pm 0.002,0.998 \pm 0.003$, and $1.057 \pm 0.004$ with $r^{2}=0.981,0.969$, and 0.942 for the 450,532 , and $632 \mathrm{~nm}$ channels, respectively. A lower limit of detection of $10 \mathrm{Mm}^{-1}$ was determined for the individual spectral measurements (twice the SD of the measurement) that can be reduced via standard error of the means when averaging spectra over longer sampling intervals. The broad spectral range (300-700 nm) and fine spectral resolution $(0.8 \mathrm{~nm})$ provided an opportunity to examine the wavelength dependence of the spectra for a diverse set of in situ ambient aerosols. Nearly all of the measured spectra exhibited curvature in logarithmic space such that second-order polynomials provided a better fit to the data than the usual linear fit of a power law representation. With either fit, evidence was presented to highlight the large deviation of an extrapolated value for $\sigma_{\text {ext }}$ beyond the fit wavelength range. This finding highlights the need for measurements that extend well into the UV, thereby limiting the need for extrapolated estimates of $\sigma_{\text {ext }}$ in that part of the spectrum.

A comparison to a previous study of spectral curvature based on Mie calculations and remote sensing data from AERONET (Schuster et al., 2006) revealed the wavelength dependence that relates the Angström exponent $(\alpha)$ to the second-order polynomial coefficients $\left(a_{1}\right.$ and $\left.a_{2}\right)$. The characteristic wavelength $\left(\lambda_{\mathrm{ch}}\right)$ of any given data set needs to be taken into account when comparing spectral curvature coefficients across data sets. Mapping the fit coefficients shows that any given $\alpha$ representation can be separated along a line in $\left(a_{1}, a_{2}\right)$ with a slope of $-2 \mathrm{LN}\left(\lambda_{\mathrm{ch}}\right)$ such that spectral curvature can be used to obtain more detailed information about aerosol size distribution. The work of Schuster et al. (2006) was directed to distinguishing different bimodal size distributions on the basis of the presence of coarse-fraction aerosols. Here, only fine-mode aerosols were sampled; nonetheless, the separation found in $\left(a_{1}, a_{2}\right)$ space across the KORUS-OC data set suggests that curvature may be used to infer more detailed size distribution information even within the fine mode alone. Size distributions were not measured aboard the R/V Onnuri, so such a study will require future ambient measurements to fill this data gap.

In Part 2 (Jordan et al., 2021), the methodology used for the filter analyses from the KORUS-OC in situ aerosol measurement suite is described with an overview of the results provided. The data from those filters include total aerosol $\sigma_{\text {abs }}$ spectra $(300-700 \mathrm{~nm})$ from glass fiber filters placed in the center of an integrating sphere, soluble aerosol absorption coefficient spectra $(300-700 \mathrm{~nm})$ from deionized water $\left(\sigma_{\mathrm{DI}-\text {-abs }}\right)$ and methanol $\left(\sigma_{\mathrm{MeOH}-\mathrm{abs}}\right)$ extracts of Teflon filters measured with a liquid waveguide capillary cell, water-soluble inorganic ion (WSII) concentrations via ion chromatography, and water-soluble organic compounds (WSOCs) that contribute to the aerosol measured using an aerosol mass spectrometer. The combination of filter-based $\sigma_{\text {abs }}$ spectra (300-700 nm) with the SpEx $\sigma_{\text {ext }}$ spectra set, allows for the calculation of spectral $\omega(300-700 \mathrm{~nm})$ for in situ aerosols. Part 2 includes a similar examination of power law and second-order polynomial representations of all four of the in situ aerosol hyperspectral data sets obtained during KORUS-OC. It also explores relationships between the optical properties and water-soluble composition information within the meteorological context of KORUS-AQ following the discussion presented here in Part 1.

Data availability. All data presented here are available from the NASA Langley Research Center Airborne Science Data for Atmospheric Composition KORUS-AQ data archive (DOI: https://doi.org/10.5067/Suborbital/KORUSAQ/DATA01; see the R/V Onnuri Ship tab, NASA, 2020). 
Supplement. The supplement related to this article is available online at: https://doi.org/10.5194/amt-14-695-2021-supplement.

Author contributions. CEJ led the experiment, analyzed the data, and wrote the manuscript. CEJ, BEA, LDZ, CHH, KLT, ELW, RFM, MAS, AJB, and CER built elements of the hardware, software, and deployment measurement system and assisted in the laboratory at NASA LaRC. CEJ, BEA, AJB, and CAC participated in the field work. RMS, BTL, and MAT deployed with the measurement suite aboard the R/V Onnuri, collected filter samples, and contributed to the manuscript. GLS, RHM, LDZ, BEA, ECC, MAS, RMS, AJB, and CAC contributed to the data analysis and the manuscript.

Competing interests. The authors declare that they have no conflict of interest.

Acknowledgements. The authors gratefully acknowledge the support of the KORUS-OC and KORUS-AQ science teams and the outstanding support provided by our South Korean partners at the Korean Institute for Ocean Science and Technology (KIOST). The authors particularly thank Anne Thompson for her support throughout this study and Fred Brechtel and Vanderlei Martins for helpful discussions.

Financial support. This research has been supported by a NASA/NIA cooperative agreement (NNL09AA00A) and a NASA grant (NNX16AD60G) through the Geostationary Coastal and Air Pollution Events (GEO-CAPE) mission pre-formulation studies.

Review statement. This paper was edited by John Sullivan and reviewed by three anonymous referees.

\section{References}

Al-Saadi, J., Carmichael, G., Crawford, J., Emmons, L., Kim, S., Song, C.-K., Chang, L.-S., Lee, G., Kim, J., and Park, R.: NASA Contributions to KORUS-AQ: An International Cooperative Air Quality Field Study in Korea, 32 pp., available at: https://espo.nasa.gov/home/korus-aq/content/KORUS-AQ_ Science_Overview_0, last access: 4 November 2015.

Anderson, T. L. and Ogren, J. A.: Determining aerosol radiative properties using the TSI 3563 integrating nephelometer, Aerosol Sci. Technol., 29, 57-69, https://doi.org/10.1080/02786829808965551, 1998.

Ångström, A.: On the atmospheric transmission of sun radiation and on dust in the air (1929), in: Selected papers on scattering in the atmosphere, SPIE Milestone Series, vol. 11, edited by: Bohren, C., SPIE, 156-166, 1989.

Bluvshtein, N., Flores, J. M., Segev, L., and Rudich, Y.: A new approach for retrieving the UV-vis optical properties of ambient aerosols, Atmos. Meas. Tech., 9, 3477-3490, https://doi.org/10.5194/amt-9-3477-2016, 2016.

Bluvshtein, N., Lin, P., Flores, J. M., Segev, L., Mazar, Y., Tas, E., Snider, G., Weagle, C., Brown, S. S., Laskin, A., and Rudich, Y.: Broadband optical properties of biomassburning aerosol and identification of brown carbon chromophores, J. Geophys. Res.-Atmos., 122, 5441-5456, https://doi.org/10.1002/2016JD026230, 2017.

Chartier, R. T. and Greenslade, M. E.: Initial investigation of the wavelength dependence of optical properties measured with a new multi-pass Aerosol Extinction Differential Optical Absorption Spectrometer (AE-DOAS), Atmos. Meas. Tech., 5, 709-721, https://doi.org/10.5194/amt-5-709-2012, 2012.

Choi, J., Park, R. J., Lee, H. M., Lee, S., Jo, D. S., Jeong, J. I., Henze, D. K., Woo, J. H., Ban, S. J., Lee, M. D., Lim, C. S., Park, M. K., Shin, H. J., Cho, S., Peterson, D., and Song, C. K.: Impacts of local vs. trans-boundary emissions from different sectors on $\mathrm{PM}_{2.5}$ exposure in South Korea during the KORUS-AQ campaign, Atmos. Environ., 203, 196-205, https://doi.org/10.1016/j.atmosenv.2019.02.008, 2019.

Crawford, J. H., Ahn, J.-Y., Al-Saadi, J., Chang, L., Emmons, L. K., Kim, J., Lee, G., Park, J.-H., Park, R., Woo, J. H., Lefer, B. L., Lee, M., Lee, T., Kim, S., Min, K.-E., Yum, S. S., Szykman, J. J., Jordan, C. E., Simpson, I. J., Fried, A., Cho, S., and Kim, Y. P.: The Korea-United States Air Quality (KORUS-AQ) field study, Elementa: Science of the Anthropocene, submitted, 2020.

Eck, T. F., Holben, B. N., Reid, J. S., Dubovik, O., Smirnov, A., O'Neill, N. T., Slutsker, I., and Kinne, S.: Wavelength dependence of the optical depth of biomass burning, urban, and desert dust aerosols, J. Geophys. Res., 104, 31333-31349, 1999.

Eck, T. F., Holben, B. N., Dubovik, O., Smirnov, A., Slutsker, I., Lobert, J. M., and Ramanathan, V.: Column-integrated aerosol optical properties over the Maldives during the northeast monsoon for 1998-2000, J. Geophys. Res., 106, 28555-28566, 2001a.

Eck, T. F., Holben, B. N., Ward, D. E., Dubovik, O., Reid, J. S., Smirnov, A., Mukelabai, M. M., Hsu, N. C., O’Neill, N. T., and Slutsker, I.: Characterization of the optical properties of biomass burning aerosols in Zambia during the 1997 ZIBBEE field campaign, J. Geophys. Res., 106, 3425-3448, 2001 b.

Eck, T. F., Holben, B. N., Ward, D. E., Mukelabai, M. M., Dubovik, O., Smirnov, A., Schafer, J. S., Hsu, N. C., Piketh, S. J., Queface, A., Le Roux, J., Swap, R. J., and Slutsker, I.: Variability of biomass burning aerosol optical characteristics in southern Africa during the SAFARI 2000 dry season campaign and a comparison of single scattering albedo estimates from radiometric measurements, J. Geophys. Res., 108, 8477, https://doi.org/10.1029/2002JD002321, 2003a.

Eck, T. F., Holben, B. N., Ward, D. E., Mukelabai, M. M., Dubovik, O., Smirnov, A., Schafer, J. S., Hsu, N. C., Piketh, S. J., Queface, A., Le Roux, J., Swap, R. J., and Slutsker, I.: Correction to "Variability of biomass burning aerosol optical characteristics in southern Africa during the SAFARI 2000 dry season campaign and a comparison of single scattering albedo estimates from radiometric measurements" by T. F. Eck et al., J. Geophys. Res., 108, 8500, https://doi.org/10.1029/2003JD001606, 2003b.

Eck, T. F., Holben, B. N., Kim, J., Beyersdorf, A. J., Choi, M., Lee, S., Koo, J. H., Giles, D. M., Schafer, J. S., Sinyuk, A., Peterson, D. A., Reid, J. S., Arola, A., Slutsker, I., 
Smirnov, A., Sorokin, M., Kraft, J., Crawford, J. H., Anderson, B. E., Thornhill, K. L., Diskin, G., Kim, S. W., and Park, S.: Influence of cloud, fog, and high relative humidity during pollution transport events in South Korea: aerosol properties and $\mathrm{PM}_{2.5}$ variability, Atmos. Environ., 232, 117530, https://doi.org/10.1016/j.atmosenv.2020.117530, 2020.

Fu, G., Hasekamp, O., Rietjens, J., Smit, M., Di Noia, A., Cairns, B., Wasilewski, A., Diner, D., Seidel, F., Xu, F., Knobelspiesse, K., Gao, M., da Silva, A., Burton, S., Hostetler, C., Hair, J., and Ferrare, R.: Aerosol retrievals from different polarimeters during the ACEPOL campaign using a common retrieval algorithm, Atmos. Meas. Tech., 13, 553-573, https://doi.org/10.5194/amt13-553-2020, 2020.

Giles, D. M., Sinyuk, A., Sorokin, M. G., Schafer, J. S., Smirnov, A., Slutsker, I., Eck, T. F., Holben, B. N., Lewis, J. R., Campbell, J. R., Welton, E. J., Korkin, S. V., and Lyapustin, A. I.: Advancements in the Aerosol Robotic Network (AERONET) Version 3 database - automated near-real-time quality control algorithm with improved cloud screening for Sun photometer aerosol optical depth (AOD) measurements, Atmos. Meas. Tech., 12, 169209, https://doi.org/10.5194/amt-12-169-2019, 2019.

Hasekamp, O. P., Fu, G., Rusli, S. P., Wu, L., Di Noia, A., aan de Brugh, J., Landgraf, J., Smit, J. M., Rietjens, J., van Amerongen, A.: Aerosol measurements by SPEXone on the NASA PACE mission: expected retrieval capabilities, J. Quant. Spectrosc. Ra., 227, 170-184, https://doi.org/10.1016/j.jqsrt.2019.02.006, 2019.

He, Q., Bluvshtein, N., Segev, L., Meidan, D., Flores, J. M., Brown, S. S., Brune, W., and Rudich, Y.: Evolution of the Complex Refractive Index of Secondary Organic Aerosols during Atmospheric Aging, Environ. Sci. Technol., 52, 3456-3465, https://doi.org/10.1021/acs.est.7b05742, 2018.

Jordan, C. E., Anderson, B. E., Beyersdorf, A. J., Corr, C. A., Dibb, J. E., Greenslade, M. E., Martin, R. F., Moore, R. H., Scheuer, E., Shook, M. A., Thornhill, K. L., Troop, D., Winstead, E. L., and Ziemba, L. D.: Spectral aerosol extinction (SpEx): a new instrument for in situ ambient aerosol extinction measurements across the UV/visible wavelength range, Atmos. Meas. Tech., 8, 4755-4771, https://doi.org/10.5194/amt-8-4755-2015, 2015.

Jordan, C. E., Crawford, J. H., Beyersdorf, A. J., Eck, T. F., Halliday, H. S., Nault, B. A., Chang, L.-S., Park, J., Park, R., Lee, G., Kim, H., Ahn, J-Y., Cho, S., Shin, H. J., Lee, J. H., Jung, J., Kim, D.-S., Lee, M., Lee, T., Whitehill, A., Szykman, J., Schueneman, M. K., Campuzano-Jost, P., Jimenez, J. L., DiGangi, J. P., Diskin, G. S., Anderson, B. E., Moore, R. H., Ziemba, L. D., Fenn, M. A., Hair, J. W., Kuehn, R. E., Holz, R. E., Chen, G., Travis, K., Shook, M., Peterson, D. A., Lamb, K. D., and Schwarz, J. P.: Investigation of factors controlling $\mathrm{PM}_{2.5}$ variability across the South Korean Peninsula during KORUS-AQ, Elementa: Science of the Anthropocene, 8, 28, https://doi.org/10.1525/elementa.424, 2020.

Jordan, C. E., Stauffer, R. M., Lamb, B. T., Novak, M., Mannino, A., Crosbie, E. C., Schuster, G. L., Moore, R. H., Hudgins, C. H., Thornhill, K. L., Winstead, E. L., Anderson, B. E., Martin, R. F., Shook, M. A., Ziemba, L. D., Beyersdorf, A. J., Robinson, C. E., Corr, C. A., and Tzortziou, M. A.: New in situ aerosol hyperspectral optical measurements over 300-700 nm - Part 2: Extinction, total absorption, water- and methanol-soluble absorption observed during the KORUS-OC cruise, Atmos. Meas. Tech., 14, 715-736, https://doi.org/10.5194/amt-14-715-2021, 2021.
Kaku, K. C., Reid, J. S., O’Neill, N. T., Quinn, P. K., Coffman, D. J., and Eck, T. F.: Verification and application of the extended spectral deconvolution algorithm $(\mathrm{SDA}+)$ methodology to estimate aerosol fine and coarse mode extinction coefficients in the marine boundary layer, Atmos. Meas. Tech., 7, 3399-3412, https://doi.org/10.5194/amt-7-3399-2014, 2014.

Kaskaoutis, D. G., Kalapureddy, M. C. R., Krishna Moorthy, K., Devara, P. C. S., Nastos, P. T., Kosmopoulos, P. G., and Kambezidis, H. D.: Heterogeneity in pre-monsoon aerosol types over the Arabian Sea deduced from ship-borne measurements of spectral AODs, Atmos. Chem. Phys., 10, 4893-4908, https://doi.org/10.5194/acp-10-4893-2010, 2010.

Kaskaoutis, D. G., Kumar Kharol, S., Sinha, P. R., Singh, R. P., Kambezidis, H. D., Rani Sharma, A., and Badarinath, K. V. S.: Extremely large anthropogenic-aerosol contribution to total aerosol load over the Bay of Bengal during winter season, Atmos. Chem. Phys., 11, 7097-7117, https://doi.org/10.5194/acp11-7097-2011, 2011.

Kaufman, Y. J.: Aerosol optical thickness and atmospheric path radiance, J. Geophys. Res., 98, 2677-2692, 1993.

Kim, H., Zhang, Q., and Heo, J.: Influence of intense secondary aerosol formation and long-range transport on aerosol chemistry and properties in the Seoul Metropolitan Area during spring time: results from KORUS-AQ, Atmos. Chem. Phys., 18, 71497168, https://doi.org/10.5194/acp-18-7149-2018, 2018.

King, M. D. and Byrne, D. M.: A method for inferring total ozone content from the spectral variation of total optical depth obtained with a solar radiometer, J. Atmos. Sci., 33, 2242-2251, 1976.

King, M. D., Byrne, D. M., Herman, B. M., and Reagan, J. A.: Aerosol size distributions obtained by inversion of spectral optical depth measurements, J. Atmos. Sci., 35, 2153-2167, 1978.

LeBlanc, S. E., Redemann, J., Flynn, C., Pistone, K., Kacenelenbogen, M., Segal-Rosenheimer, M., Shinozuka, Y., Dunagan, S., Dahlgren, R. P., Meyer, K., Podolske, J., Howell, S. G., Freitag, S., Small-Griswold, J., Holben, B., Diamond, M., Wood, R., Formenti, P., Piketh, S., Maggs-Kölling, G., Gerber, M., and Namwoonde, A.: Above-cloud aerosol optical depth from airborne observations in the southeast Atlantic, Atmos. Chem. Phys., 20, 1565-1590, https://doi.org/10.5194/acp-20-1565-2020, 2020.

Moosmüller, H. and Chakrabarty, R. K.: Technical Note: Simple analytical relationships between Ångström coefficients of aerosol extinction, scattering, absorption, and single scattering albedo, Atmos. Chem. Phys., 11, 10677-10680, https://doi.org/10.5194/acp-11-10677-2011, 2011.

NASA: KORUS-AQ - An International Cooperative Air Quality Field Study in Korea, NASA Langley Research Center Airborne Science Data for Atmospheric Composition, KORUS-AQ data archive, https://doi.org/10.5067/Suborbital/KORUSAQ/DATA01, 2020.

Nault, B. A., Campuzano-Jost, P., Day, D. A., Schroder, J. C., Anderson, B., Beyersdorf, A. J., Blake, D. R., Brune, W. H., Choi, Y., Corr, C. A., de Gouw, J. A., Dibb, J., DiGangi, J. P., Diskin, G. S., Fried, A., Huey, L. G., Kim, M. J., Knote, C. J., Lamb, K. D., Lee, T., Park, T., Pusede, S. E., Scheuer, E., Thornhill, K. L., Woo, J.-H., and Jimenez, J. L.: Secondary organic aerosol production from local emissions dominates the organic aerosol budget over Seoul, South Korea, during KORUS-AQ, Atmos. Chem. Phys., 18, 17769-17800, https://doi.org/10.5194/acp-18-177692018, 2018. 
O’Neill, N. T., Dubovik, O., and Eck, T. F.: Modified Ångström exponent for the characterization of submicrometer aerosols, Appl. Optics, 40, 2368-2375, 2001.

O'Neill, N. T., Eck, T. F., Smirnov, A., Holben, B. N., and Thulasiraman S.: Spectral discrimination of coarse and fine mode optical depth, J. Geophys. Res.-Atmos., 108, 4559, https://doi.org/10.1029/2002JD002975, 2003.

O’Neill, N. T., Eck, T. F., Reid, J. S., Smirnov, A., and Pancrati, O.: Coarse mode optical information retrievable using ultraviolet to short-wave infrared Sun photometry: Application to United Arab Emirates Unified Aerosol Experiment data, J. Geophys. Res.Atmos., 113, D05212, https://doi.org/10.1029/2007JD009052, 2008.

Ogren, J. A., Wendell, J., Andrews, E., and Sheridan, P. J.: Continuous light absorption photometer for long-term studies, Atmos. Meas. Tech., 10, 4805-4818, https://doi.org/10.5194/amt10-4805-2017, 2017.

Peterson, D. A., Hyer, E. J., Han, S.-O., Crawford, J. H., Park, R. J., Holz, R., Kuehn, R. E., Eloranta, E., Knote, C., Jordan, C. E., and Lefer, B. L.: Meteorology influencing springtime air quality, pollution transport, and visibility in Korea, Elementa: Science of the Anthropocene, 7, 57, https://doi.org/10.1525/elementa.395, 2019.

Rao, B. M. and Niranjan, K.: Optical properties of the South Asian winter haze at a tropical coastal site in India, Atmos. Environ., 54, 449-455, https://doi.org/10.1016/j.atmosenv.2012.02.016, 2012.

Reid, J. S., Eck, T. F., Christopher, S. A., Hobbs, P. V., and Holben, B.: Use of the Angstrom exponent to estimate the variability of optical and physical properties of aging smoke particles in Brazil, J. Geophys. Res., 104, 27473-27489, 1999.

Remer, L. A., Davis, A. B., Mattoo, S., Levy, R. C., Kalashnikova, O. V., Coddington, O., Chowdhary, J., Knobelspiesse, K., Xu, X., Ahmad, Z., Boss, E., Cairns, B., Dierssen, H. M., Diner, D. J., Franz, B., Frouin, R., Gao, B.-C., Ibrahim, A., Martins, J. V., Omar, A. H., Torres, O., Xu, F., and Zhai, P.W.: Retrieving Aerosol Characteristics From the PACE Mission, Part 1: Ocean Color Instrument, Front. Earth Sci., 7, 152, https://doi.org/10.3389/feart.2019.00152, 2019a.

Remer, L. A., Knobelspiesse, K., Zhai, P.-W., Xu, F., Kalashnikova, O. V., Chowdhary, J., Hasekamp, O., Dubovik, O., Wu, L., Ahmad, Z., Boss, E., Cairns, B., Coddington, O., Davis, A. B., Dierssen, H. M., Diner, D. J., Franz, B., Frouin, R., Gao, B.-C., Ibrahim, A., Levy, R. C., Martins, J. V., Omar, A. H., and Torres, O.: Retrieving Aerosol Characteristics From the PACE Mission, Part 2: Multi-Angle and Polarimetry, Front. Environ. Sci., 7, 94, https://doi.org/10.3389/fenvs.2019.00094, 2019 b.
Schuster, G. L., Dubovik, O., and Holben, B. N.: Angstrom exponent and bimodal aerosol size distributions, J. Geophys. Res., 111, D07207, https://doi.org/10.1029/2005JD006328, 2006.

Smit, J. M., Rietjens, J. H. H., van Harten, G., Noia, A. D., Laauwen, W., Rheingans, B. E., Diner, D. J., Cairns, B., Wasilewski, A., Knobelspiesse, K. D., Ferrare, R., and Hasekamp, O. P.: SPEX airborne spectropolarimeter calibration and performance, Appl. Optics, 58, 5695-5719, https://doi.org/10.1364/AO.58.005695, 2019.

Thompson, A. M., Stauffer, R. M., Boyle, T. P., Kollonige, D. E., Miyazaki, K., Tzortziou, M., Herman, J. R., Abuhassan, N., Jordan, C. E., and Lamb, B. T.: Comparison of near surface $\mathrm{NO}_{2}$ pollution with Pandora total column $\mathrm{NO}_{2}$ during the Korea-United States Ocean Color (KORUS OC) Campaign, J. Geophys. Res.-Atmos., 124, 13560-13575, https://doi.org/10.1029/2019JD030765, 2019.

Tzortziou, M., Parker, O., Lamb, B., Herman, J., Lamsal, L., Stauffer, R., and Abuhassan, N.: Atmospheric trace gas $\left(\mathrm{NO}_{2}\right.$ and $\mathrm{O}_{3}$ ) variability in Korean coastal waters, implications for remote sensing of coastal ocean color dynamics, Remote Sens.-Basel, 10, 1587, https://doi.org/10.3390/rs10101587, 2018.

US-Korean Steering Group: Risk reduction measurements for GEO-CAPE: A US-Korea joint field campaign (US-Korea JFC) in the East Sea and Yellow Sea, 18 pages, available at: https: //geo-cape.larc.nasa.gov/wp-content/uploads/sites/142/2020/08/ KORUS_OC_WhitePaper_2016_Field_20150205_final.pdf, last access: 29 October 2015.

Washenfelder, R. A., Flores, J. M., Brock, C. A., Brown, S. S., and Rudich, Y.: Broadband measurements of aerosol extinction in the ultraviolet spectral region, Atmos. Meas. Tech., 6, 861-877, https://doi.org/10.5194/amt-6-861-2013, 2013.

Washenfelder, R. A., Attwood, A. R., Brock, C. A., Guo, H., Xu, L., Weber, R. J., Ng, N. L., Allen, H. M., Ayres, B. R., Baumann, K., Cohen, R. C., Draper, D. C., Duffey, K. C., Edgerton, E., Fry, J. L., Hu, W. W., Jimenez, J. L., Palm, B. B., Romer, P., Stone, E. A., Wooldridge, P. J., and Brown, S. S.: Biomass burning dominates brown carbon absorption in the rural southeastern United States, Geophys. Res. Lett., 42, 653-664, https://doi.org/10.1002/2014GL062444, 2015.

Werdell, P. J., Behrenfeld, M. J., Bontempi, P. S., Boss, E., Cairns, B., Davis, G. T., Franz, B. A., Gliese, U. B., Gorman, E. T., Hasekamp, O., Knobelspiesse, K. D., Mannino, A., Martins, J. V., McClain, C. R., Meister, G., and Remer, L. A.: The Plankton, Aerosol, Cloud, ocean Ecosystem mission status, science, advances, B. Am. Meteorol. Soc., 1775-1794, https://doi.org/10.1175/BAMS-D-18-0056.1, 2019.

White, J. U.: Long optical paths of large aperture, J. Opt. Soc. Am., 32, 285-288, 1942. 